\title{
The Mcs4 response regulator coordinately controls the stress-activated Wak1-Wis1-Sty1 MAP kinase pathway and fission yeast cell cycle
}

\author{
Jia-Ching Shieh, Marc G. Wilkinson, Vicky Buck, Brian A. Morgan, ${ }^{1}$ Kozo Makino, ${ }^{2}$ and \\ Jonathan B.A. Millar ${ }^{3}$ \\ Division of Yeast Genetics, National Institute for Medical Research, The Ridgeway, Mill Hill, London NW7 1AA, UK
}

\begin{abstract}
The fission yeast Sty1 MAP kinase is required for cell cycle control, initiation of sexual differentiation, and protection against cellular stress. Like the mammalian JNK/SAPK and p38/CSBP1 MAP kinases, Sty1 is activated by a range of environmental insults including osmotic stress, hydrogen peroxide, menadione, heat shock, and the protein synthesis inhibitor anisomycin. We have identified an upstream regulator that mediates activation of the Sty1 MAP kinase by multiple environmental stresses as the product of the mitotic catastrophe suppressor, mcs4. Mcs4 is structurally and functionally homologous to the budding yeast $\overline{\mathrm{SSK} 1}$ response regulator, suggesting that the eukaryotic stress-activated MAP kinase pathway is controlled by a conserved two-component system. Mcs4 acts upstream of Wak1, a homolog of the SSK2 and SSK22 MEK kinases, which transmits the stress signal to the Wis1 MEK. We show that the Wis1 MEK is controlled by an additional pathway that is independent of both Mcs4 and the Wak1 MEK kinase. Furthermore, we demonstrate that Mcs4 is required for the correct timing of mitotic initiation by mechanisms both dependent and independent on Sty1, indicating that Mcs4 coordinately controls cell cycle progression with the cellular response to environmental stress.
\end{abstract}

[Key Words: Stress-activated MAP kinase; response regulator; two-component system; cell cycle; Schizosaccharomyces pombe]

Received December 12, 1996; revised version accepted March 13, 1997.

In recent years it has become apparent that the molecular machinery that governs the eukaryotic cell cycle has been evolutionarily conserved. In eukaryotic cells both the onset of DNA replication (S phase) and initiation of mitosis ( $M$ phase) are triggered by members of the cyclindependent kinase (Cdk) family in association with a regulatory cyclin subunit. In the fission yeast both major transitions are catalyzed by a single gene product, $\mathrm{Cdc} 2$ (Nurse and Bissett 1981). At the initiation of mitosis the Cdc2-Cdc13 (cyclin B) complex is activated by tyrosine dephosphorylation of the catalytic kinase subunit by the Cdc25 phosphatase (for review, see Millar and Russell 1992). The complex is maintained in an inactive state in interphase by phosphorylation of $\mathrm{Cdc} 2$ by two functionally overlapping tyrosine kinases, Weel and Mik1 (Rus-

Present addresses: ${ }^{1}$ Department of Biochemistry and Genetics, The Medical School, The University of Newcastle-upon-Tyne, Newcastleupon-Tyne NE2 4HH, UK; ${ }^{2}$ Department of Molecular Microbiology, Research Institute for Microbial Diseases, Osaka University, 3-1 Yamadaoka Suita, Osaka 565, Japan.

${ }^{3}$ Corresponding author.

E-MAIL j-millar@nimr.mrc.ac.uk; FAX (0181) 9138536. sell and Nurse 1987; Lundgren et al. 1991). The Cdc2 kinase is additionally controlled in the $G_{1}$ phase of the cell cycle by direct binding of an inhibitor, Rum 1 (Correa-Bordes and Nurse 1995). Extensive genetic analysis in Schizosaccharomyces pombe has revealed several other loci that show genetic interaction with the core elements described above and, by inference, also encode proteins that control the fission yeast cell cycle. For example in $c d c 2-3 w$ wee $1-50$ cells, which express a dominantly active Cdc2 kinase and a temperature-sensitive Weel kinase, hyperactivation of the Cdc2 kinase induces a premature, lethal mitotic initiation known as mitotic catastrophe (Russell and Nurse 1987). This phenotype is suppressed by mutation in one of six genes (mcs1-mcs6, for mitotic catostrophe suppression) (Molz et al. 1989). The mcs 2 and mcs6 (also known as crk1/mop1) genes encode for a cyclin $\mathrm{H}$-like molecule and its cyclin-dependent kinase, respectively, that interact to form fission yeast Cdc2-activating kinase (or CAK) (Buck et al. 1996; Damagnez et al. 1996). Despite the identification of these gene products our understanding of how the fission yeast cell cycle is controlled either by external growth regulatory cues, such as environmental stress, or inter- 
nal checkpoint mechanisms, such as DNA damage, remains rudimentary.

Recently we have uncovered a mitogen-activated protein (MAP) kinase pathway that controls mitotic initiation in fission yeast in response to environmental stress, the central elements of which are the Styl MAP kinase (also known as Spc1 and Phh1) and the Wis1 MAP kinase kinase (MEK) (Warbrick and Fantes 1991; Millar et al. 1995; Shiozaki and Russell 1995; Kato et al. 1996). Cells lacking either Sty1 or Wis1 are considerably elongated at cell division and display strong genetic interactions with known mitotic entry mutants, in particular the Cdc25 tyrosine phosphatase (Warbrick and Fantes 1991; Millar et al. 1992, 1995; Millar and Russell 1992; Shiozaki and Russell 1995). A direct downstream target of the Styl MAP kinase has been identified as Atfl, a homolog of the human ATF2 transcription factor, which is required for induction of genes required for meiosis and protection against environmental stress (Takeda et al. 1995; Shiozaki and Russell 1996; Wilkinson et al. 1996). Cells lacking Atfl, however, have no cell size at division defect, suggesting that an alternative Styl substrate controls mitotic initiation.

The Styl MAP kinase is most structurally similar to the budding yeast HOG1 MAP kinase, both of which are required for the cellular response to osmotic stress in their respective organisms (Brewster et al. 1993; Millar et al. 1995; Shiozaki and Russell 1995). The upstream activators of the budding yeast HOG1 MAP kinase have been identified genetically and biochemically. In particular, hyperosmolarity is thought to cause inactivation of a transmembrane histidine kinase, SLN1, that normally maintains the HOG1 MAP kinase inactive (Maeda et al. 1994, 1995). SLN1 autophosphorylation initiates a phospho-relay system in which a phosphate group is transferred from the SLN1 response regulator domain to a histidine residue in the YPD1 protein and then to a conserved aspartate residue in the SSK1 response regulator (Posas et al. 1996). This phospho-relay system is similar to a number of two-component systems that function in bacteria (Stock et al. 1989; Parkinson 1993). The unphosphorylated form of the SSK1 response regulator activates one of two functionally overlapping MEK kinases, SSK2 and SSK22, though the mechanism by which this is acheived is not known (Maeda et al. 1994, 1995). SSK2 and SSK22 kinase activation leads to the sequential phosphorylation and activation of the HOG4/ PBS2 MEK and HOG1 MAP kinases (Brewster et al. 1993; Maeda et al. 1994, 1995). A second transmembrane osmosensor, $\mathrm{SHO} 1$, has been described in budding yeast, which interacts directly with a proline rich domain in the amino terminus of the PBS2/HOG4 MEK (Maeda et al. 1995). Importantly, although the budding yeast HOG1 MAP kinase is activated only by osmotic stress, the fission yeast Sty1 MAP kinase and the mammalian stress-activated SAPK/JNK and p38/CSBP1 MAP kinases are activated by a range of environmental insults, including osmotic stress, oxidative stress, ultraviolet (UV) light, DNA damaging agents, heat shock, and the protein synthesis inhibitor anisomycin (Brewster et al.
1993; Dérijard et al. 1994; Galcheva-Gargova et al. 1994; Han et al. 1994; Kyriakis et al. 1994; Lee et al. 1994; Rouse et al. 1994; Schüller et al. 1994; Millar et al. 1995; Shiozaki and Russell 1995; Degols et al. 1996). This suggests that the upstream regulators of the mammalian and fission yeast pathways may be structurally similar. However, the mechanism by which these environmental stresses are sensed and transduced to the fission yeast Sty1 and mammalian SAPK/JNK and p38/CSBP1 MAP kinases is, at present, a mystery.

In this paper we demonstrate that activation of the Sty1 MAP kinase by multiple stresses requires a response regulator encoded by the mitotic catastrophe suppressor gene mcs4. Mcs4 is structurally and functionally similar to the budding yeast SSK1 gene product and acts upstream of Wak1, a homolog of the SSK2 and SSK22 MEK kinases, which transmits the stress signal to the Wis1 MEK. These results indicate a remarkable structural conservation in the upstream components of the budding yeast HOG1 and fission yeast Styl MAP kinase pathways, even though the two pathways are regulated by distinct extracellular stimuli. In addition we show that Mcs4 is required for controlling the timing of mitotic initiation by a Styl-independent pathway, suggesting that cell cycle progression and Styl MAP kinase activation are coordinately controlled by a two-component system in fission yeast.

\section{Results}

Mcs4 is a novel mitotic regulator required for Wis1 function

Hyperactivation of the Sty 1 MAP kinase pathway causes fission yeast cells to cease proliferating and undergo a lethal cell lysis. This is observed when two functionally overlapping MAP kinase phosphatases, Pyp1 and Pyp2, are inactivated (Millar et al. 1995). A similar phenotype is observed when the Wis1 MEK is highly overexpressed from the thiamine-repressible $n m t 1$ promoter (Fig. 1A). We have identified two mutants that suppress this phenotype. These are sty1-1, which harbors a null allele of the Styl MAP kinase, and mcs4-13 cells (Fig. 1A). The mcs4-13 mutation was originally isolated by its ability to suppress the lethal hyperactivation of the Cdc2 kinase in a cdc2-3w wee1-50 strain (Molz et al. 1989). Like cells lacking either wis1 or sty1, mcs4-13 mutant cells display a cell size at division defect in that they divide at $19.1 \pm 1.1 \mu \mathrm{m}$ relative to $14.2 \pm 0.3 \mu \mathrm{m}$ for wild type (Table 1). As is the case with $\Delta$ wis 1 and $\Delta$ sty 1 mutants, the effect of mcs4-13 on cell size at division is dramatically exaggerated in cdc25-22 cells that harbor a temperature-sensitive version of the $\mathrm{Cdc} 25$ protein phosphatase and are partially defective for mitotic initiation at $26^{\circ} \mathrm{C}$. Whereas Cdc25-22 cells divide at $21.9 \pm 0.8 \mu \mathrm{m}$ at $26^{\circ} \mathrm{C}$, mcs $4-13 \mathrm{cdc} 25-22$ double mutants are extremely long, dividing at $38.9 \pm 10.9 \mu \mathrm{m}$ (Table 1). These results confirm that mcs 4 has an important role in controlling mitotic initiation in fission yeast and further suggest that mcs 4 acts either as an upstream activator or downstream target of the Sty1 kinase. 
A

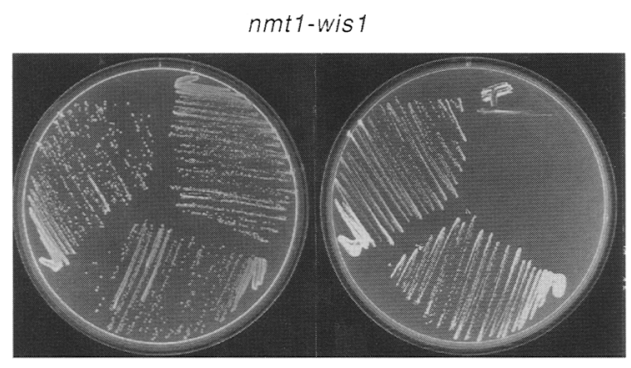

+ thiamine

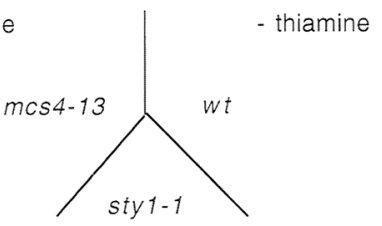

B

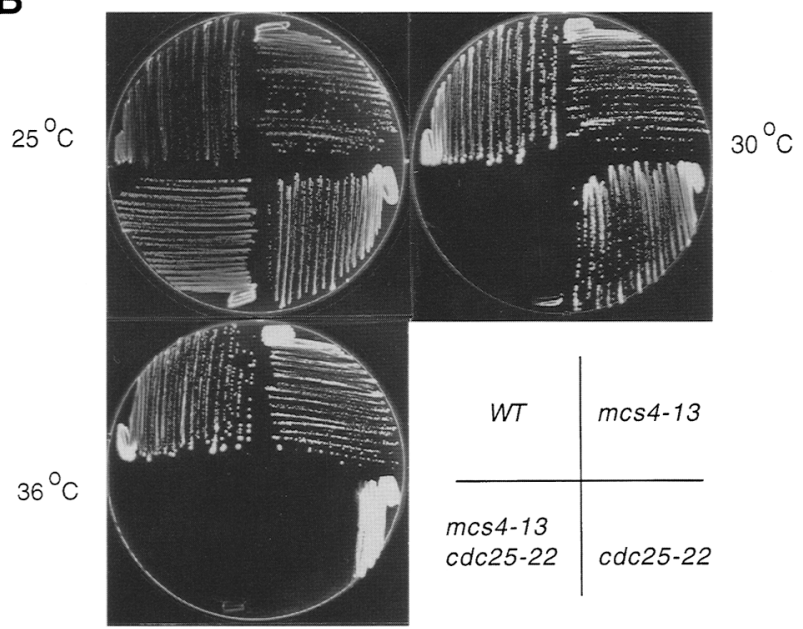

Figure 1. Mcs4 is a mitotic inducer that interacts genetically with the Wisl MEK. (A) Loss of mcs4 suppresses overexpression of wis1. Wild-type (PR109), sty1-1 (JM1144), or mcs4-13 cells (JM1354) were transformed with pREP1-wisl. Transformants were selected on minimal medium lacking leucine containing $10 \mu \mathrm{M}$ thiamine and then streaked onto the same medium (t)hiamine) or the same medium lacking thiamine $(-)$ and growth of the cells monitored after 3 days at $30^{\circ} \mathrm{C}$. (B) Mcs 4 regulates the initiation of mitosis. Wild-type (WT) (PR 109), mcs4-13 (JM1354), cdc25-22 (JM1351), or mcs4-13 cdc25-22 (JM1303) cells were grown on YEPD at $25^{\circ} \mathrm{C}$ and then streaked onto YEPD plates at $25^{\circ} \mathrm{C}, 30^{\circ} \mathrm{C}$, or $36^{\circ} \mathrm{C}$. Growth of the strains after 3 days is shown.

To examine the mechanism by which the mcs $4-13$ mutant suppresses the lethal hyperactivation of wis1, we first attempted to clone the mcs 4 gene. To do this we took advantage of the observation that mcs4-13 cdc25-22 double-mutant cells undergo cell cycle arrest at $30^{\circ} \mathrm{C}$, at which temperature mcs4-13 and $c d c 25-22$ single mutants are able to proliferate normally (Fig. 1B). A genomic library was introduced into mcs $4-13$ cdc25-22 ura4-D18 cells, and from a total of 50,000 transformants isolated at $25^{\circ} \mathrm{C}, 53$ plasmid dependent colonies grew at $30^{\circ} \mathrm{C}$. Of these suppressors, 45 represented already known genes, cdc25 (34 clones), nim1/cdr1 (five clones), and wis1 (six clones). The restriction maps of the remaining eight suppressors were found to be related and represented three distinct overlapping clones. The restriction map of the smallest clone, pURB1-Mcs4-1, is not similar to mitotic regulators identified previously (Fig. $2 \mathrm{~A}$ ).

To determine the relationship between the mcs4-13 mutation and the pURB1-Mcs4-1 genomic clone, the open reading frame (ORF) of pURB1-Mcs4-1 was interrupted by the $\mathrm{ura}^{+}$gene (Fig. 2A). The resulting plasmid pURB1-Mcs4::ura4 was unable to rescue a mcs4-13 cdc25-22 mutant (data not shown). pURB1-Mcs4::ura4 was linearized and stably integrated into a leu1-32/leu132 ura4-D18/ura4-D18 ade6-M216/ade6-M210 his7$366 /$ his 7-366 $h^{+} / h^{-}$diploid strain. Tetrad dissection of asci from heterozygous diploids gave rise to four viable spores on germination that showed a $2: 2$ segregation of uracil auxotrophs to uracil prototrophs (data not shown). All uracil prototrophs were found to be elongated to the same extent as mcs4-13 cells and synthetically lethal in combination with the $c d c 25-22$ mutation at $30^{\circ} \mathrm{C}$ (data not shown). Random spore analysis of a cross between these uracil prototrophs and mcs $4-13$ cells revealed that out of 3000 spores analyzed no wild-type recombinants could be isolated. We conclude that mcs $4-13$ cells harbor a null mutation in a novel mitotic regulator in fission yeast.

\section{Mcs4 is part of a conserved two-component system}

Sequencing of the pURB1-Mcs4-1 clone revealed a single open reading frame of 1566 bp capable of encoding a polypeptide of 522 amino acids. The predicted protein sequence was analyzed against current databases and found to contain a response regulator domain in its carboxyl terminus, which is most commonly found in components of bacterial two-component systems, but more recently also have been found in eukaryotes such as Dictyostelium discoideum, Saccharomyces cerevisiae, and Arabodopsis thaliana (Chang et al. 1993; Ota and Varshavsky 1993; Schuster et al. 1996; Wang et al. 1996).

Table 1. Loss of mcs4 or wakl delays the timing of mitosis

\begin{tabular}{lcc}
\hline & $\begin{array}{c}\text { Temp. } \\
\left({ }^{\circ} \mathrm{C}\right)\end{array}$ & $\begin{array}{c}\text { Cell size } \\
\text { at division } \\
\langle\mu \mathrm{m})\end{array}$ \\
\hline Wild type & 26 & $14.2 \pm 0.3$ \\
mcs4-13 & 26 & $19.1 \pm 1.1$ \\
wak1::ura4 & 26 & $16.5 \pm 1.3$ \\
wis1::ura4 & 26 & $23.1 \pm 2.1$ \\
cdc25-22 & 26 & $21.9 \pm 0.8$ \\
mcs4-13 cdc25-22 & 26 & $38.9 \pm 7.9$ \\
wak1::ura4 cdc25-22 & 26 & $28.5 \pm 4.5$ \\
wis1::ura4 cdc25-22 & 26 & $\mathrm{Cdc}$ \\
\hline Cell
\end{tabular}

Cell size measurements of septated cells grown in minimal medium. The temperature at which the measurements were made is indicated. Measurements were the mean of at least 30 individual determinations $( \pm$ S.D.)

${ }^{\mathrm{a} C}$ Cell division cycle arrest. 
A

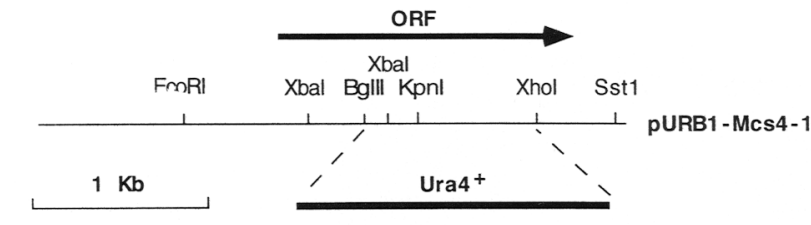

B

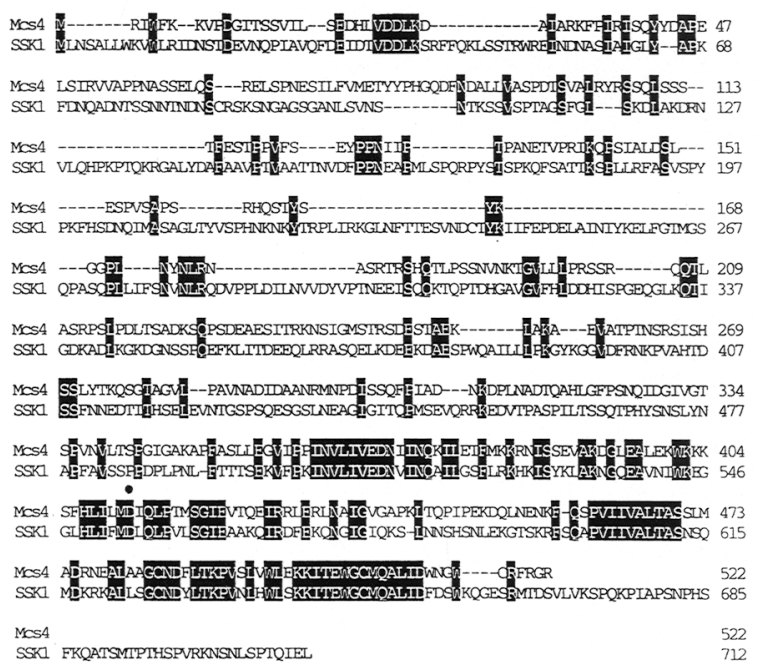

Figure 2. Mcs4 is a response regulator. (A) Restriction map of the insert of pURB1-Mcs4-1. The position of the ORF is shown. The arrow indicates the direction, with the arrowhead at the 3 ' end of the gene. One-kilobase intervals are marked under the map. A map of the pURB1-Mcs4::ura4 construction is also shown. (B) Mcs4 is homologous to response regulator proteins. Alignment of the complete Mcs4 amino acid sequence to that of budding yeast SSK1 protein is shown. Boxes indicate identities between the two proteins. An asterisk marks the location of the phosphate acceptor residue in SSK1 and Mcs4 response regulator domains. The nucleotide sequence of the mcs4 gene will appear in the EMBL, GenBank, and DDBJ Nucleotide Sequence Databases under accession no. Y11927.

Mcs4 is most closely related to the SSK1 protein from the budding yeast $S$. cerevisiae, which is involved in a phosphorelay system that regulates the HOG1 MAP kinase cascade in response to external osmolarity (Maeda et al. 1994). Mcs4 is 55\% identical to SSKl in the carboxy-terminal response regulator domain, as compared with an average of $18 \%$ identity to a variety of bacterial response regulators, but shares little homology outside of this region (Fig. 2B). Budding yeast contains two nontransmembrane proteins that contain response regulator domains, namely, SSK1 and SKN7 (also known as BRY1/ POS9). The SKN7 protein plays an important role in cell wall biosynthesis, $\mathrm{G}_{1}$ cyclin expression, and induction of gene expression in response to oxidative stress (Brown et al. 1993; Morgan et al. 1995; Krems et al. 1996). To assess whether Mcs4 may be functionally related to these gene products, SSK1 and SKN7 were cloned behind the thiamine-repressible nmt1 promoter and expressed in mcs4$13 c d c 25-22$ cells. As the results in Figure 3A demon- strate, SSK1 but not SKN7 was able to rescue the cell cycle arrest resulting from loss of mcs4. Together these results indicate that Mcs4 is both structurally and functionally related to the SSK1 gene product of budding yeast.

Inactivation of the SLN1 histidine kinase results in dephosphorylation of SSK1 on a conserved aspartate residue (D554) in the response regulator domain, and promotes activation of the HOG1 MAP kinase pathway (Maeda et al. 1994). The equivalent residue in Mcs4 is aspartate D412. To assess whether phosphorylation of Mcs4 in the putative response regulator domain is required for its mitotic function, aspartate $\mathrm{D} 412$ was mutated to either asparagine (D412N) or glutamic acid (D412E), which are not substrates for phosphorylation. Full-length forms of either wild-type mcs 4 or the sitedirected mutants were expressed behind a crippled version of the $n m t 1$ promoter and introduced into mcs4-13 $c d c 25-22$ cells. Both mcs4(D412N) and mcs4(D412E) mutants were able to rescue the cell cycle arrest of this strain as efficiently as wild-type $\operatorname{mcs} 4$ at $30^{\circ} \mathrm{C}$, indicating that phosphorylation of Mcs4 at aspartate D412 is not required for its cell cycle function. We assume that glutamic acid does not mimic a constitutively phosphorylated aspartic acid residue in the response regulator domain.

Mcs4 is required for stress-induced gene expression and activation of the Sty1 MAP kinase

The Sty1 MAP kinase, like the human INK/SAPK and p38 enzymes, is activated by a variety of environmental insults including osmotic stress, heat shock, and oxidative stress (Millar et al. 1995; Degols et al. 1996). We show here that Styl can also be activated by the protein synthesis inhibitor ansiomycin. Activation of the Wis1Sty1-Atf1 pathway by these stresses causes induction of a number of genes, including the pyp2 MAP kinase phosphatase, which acts in a feedback loop to attenuate Styl activity (Millar et al. 1995; Degols et al. 1996; Wilkinson et al. 1996). To examine whether mcs4 is required for activation of the Sty1 MAP kinase pathway, wild-type or $\Delta m c s 4$ cells were incubated in the presence of $0.6 \mathrm{M} \mathrm{KCl}$, $1 \mathrm{mM} \mathrm{H}_{2} \mathrm{O}_{2}$, or $10 \mu \mathrm{g} / \mathrm{ml}$ of anisomycin or given a mild heat shock for various times and then the level of pyp2 expression examined by Northern blot analysis. As the results in Figure 4A show, induction of pyp 2 was reduced dramatically in $\Delta m c s 4$ cells in response to every stress employed, although some expression of the pyp2 mRNA was observed after the peak expression of $p y p 2$ observed in wild type cells. Notably, induction of pyp2 mRNA by these stresses is absolutely dependent on the Styl MAP kinase as no induction is observed in $\Delta$ sty 1 cells (Fig. 4A). Northern blots were reprobed with the $c d c 2$, act1, wis1, or sty1 genes, the corresponding mRNAs of which were not altered by loss of mcs 4 or in response to stress (data not shown). To confirm this result, we took advantage of previous observations that the catalase (ctt1) and glyceraldehyde-3-phosphate dehydrogenase (gpd1) genes are also under control of the Wis1-Sty1-Atf1 pathway 
Figure 3. Mcs4 is functionally related to budding yeast SSK1. (A) SSK1 rescues loss of Mcs4. mcs4-13 cdc25-22 cells (JM1303) were transformed with a control plasmid pREP42 (pControl), pREP42-SSK1 (pSSK1), or pREP42-SKN7 (pSKN7) expressing either the SSK1 or SKN7 ORFs, respectively, behind the thiamine-repressible $n m t 1$ promoter. Transformants were grown and streaked on minimal medium lacking thiamine and uracil and growth of the cells monitored after 3 days at temperatures shown. (B) Phosphorylation of residue D412 is not required for Mcs4 function. mcs4-13 cdc25-22 cells (JM1303) were transformed with a control plasmid pREP42, pREP42-mcs4, pREP42$\operatorname{mcs} 4(D 412 N)$, or pREP42-mcs4(D412E) expressing either the wild-type or mutant versions of the mcs4 ORF, respectively, behind the thiamine-repressible nmt1 promoter. Transformants were grown on minimal medium lacking thiamine and uracil and growth of the cells monitored after 3 days at temperatures shown.

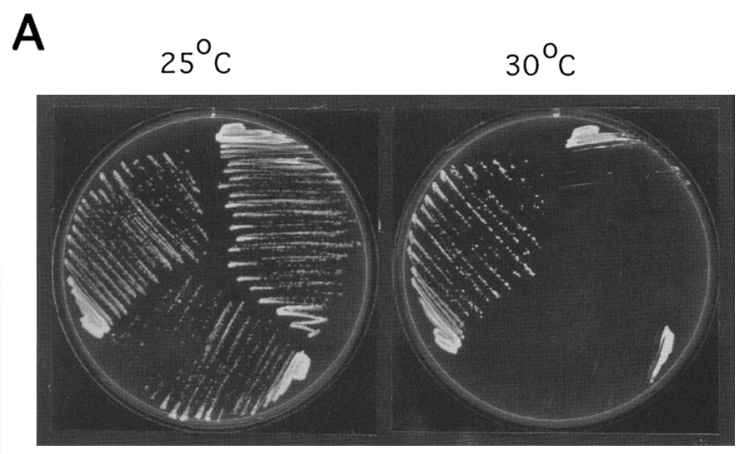

$\operatorname{mcs} 4-13 c d c 25-22$

B

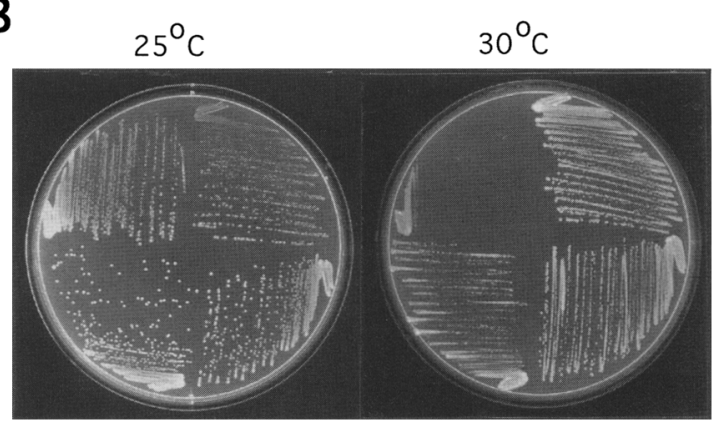

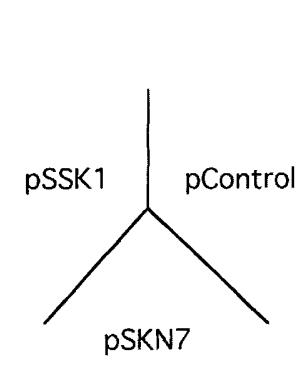

$\operatorname{mcs} 4-13 \operatorname{cdc} 25-22$

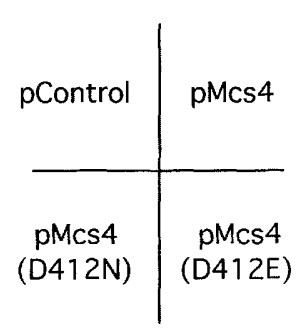

(Wilkinson et al. 1996). Wild-type or $\Delta m c s 4$ cells were stimulated with either $0.6 \mathrm{M} \mathrm{KCl}$ or $1 \mathrm{mM} \mathrm{H}_{2} \mathrm{O}_{2}$ and the induction of the ctt1 and gpd1 genes analyzed by Northern blot. Stress-induced expression of both the $c t t 1$ and gpd 1 mRNAs also was reduced dramatically in $\Delta m c s 4$ cells relative to wild type. These results indicate that the Mcs4 response regulator is required for induction of gene expression by multiple environmental insults.

To assess whether the effect of mcs 4 on stress-induced gene expression is at the level of transcription or via controlling the activity of the Styl MAP kinase, we developed a coupled affinity-kinase assay to measure endogenous Styl activity. This assay is based on our previous observation that a glutathione $S$-transferase (GST)Atf1 fusion protein specifically associates with and is a substrate for the Styl kinase (Wilkinson et al. 1996). Sty l was precipitated from extracts of either wild-type or $\Delta m c s 4$ cells that had been challenged with either $0.6 \mathrm{M}$ $\mathrm{KCl}$ or $1 \mathrm{mM} \mathrm{H}_{2} \mathrm{O}_{2}$ or given a mild heat shock and assayed for activity against the GST-Atf1 protein as substrate. As the results in Figure 4D show, activation of Styl was dramatically lowered in cells lacking mes 4 in response to all three stresses, although some activation was again observed at later time points (Fig. 4D). Under the conditions employed in these experiments, no detectable activity could be precipitated from cells lacking the Wisl MEK (data not shown). Similar results were found when cells were challenged with either the superoxide generator menadione or the protein synthesis inhibitor anisomycin (data not shown). It should be noted that the effect of anisomycin is not dependent on protein synthesis inhibition, because cycloheximide at concentrations that inhibit $98 \%$ of protein synthesis does not induce pyp2 expression or activate the Styl MAP kinase (Wilkinson et al. 1996). Together these results indicate that the Mcs4 protein is required for Sty1 MAP kinase activation in response to multiple independent environmental stresses. These results are in striking contrast to budding yeast SSK1, which is required for activation of HOG1 only in response to osmotic stress. Furthermore, because Styl is activated by the Wis1 MEK, a prediction from this is that Wisl activity is lower in the absence of Mcs4. This would explain why lethal overexpression of wis1 is suppressed in mcs4-13 cells (Fig. 1).

\section{Mcs4 acts upstream of Wak1, a homolog of the SSK2 and SSK22 MEK kinases}

The budding yeast SSK1 gene product is thought to regulate the HOG1 MAP kinase pathway by controlling the activity of the SSK2 and SSK22 MEK kinases (Maeda et al. 1994). We reasoned that Mcs4 may control the activity of a structural homolog of SSK2 and SSK22 in fission yeast. In a search of the $S$. pombe sequence databases we identified an ORF on chromosome I with high sequence homology to SSK2 and SSK22. The restriction map of this ORF is presented in Figure 5A. We have termed this kinase Wak1, for Wis 1 -activating kinase. Wak1 encodes a predicted 1307 -amino-acid protein that is $50 \%$ identical to SSK2 and $49 \%$ identical to SSK22 in the carboxyterminal catalytic kinase domain as compared with an average of $26 \%$ identity with other kinases. Importantly 


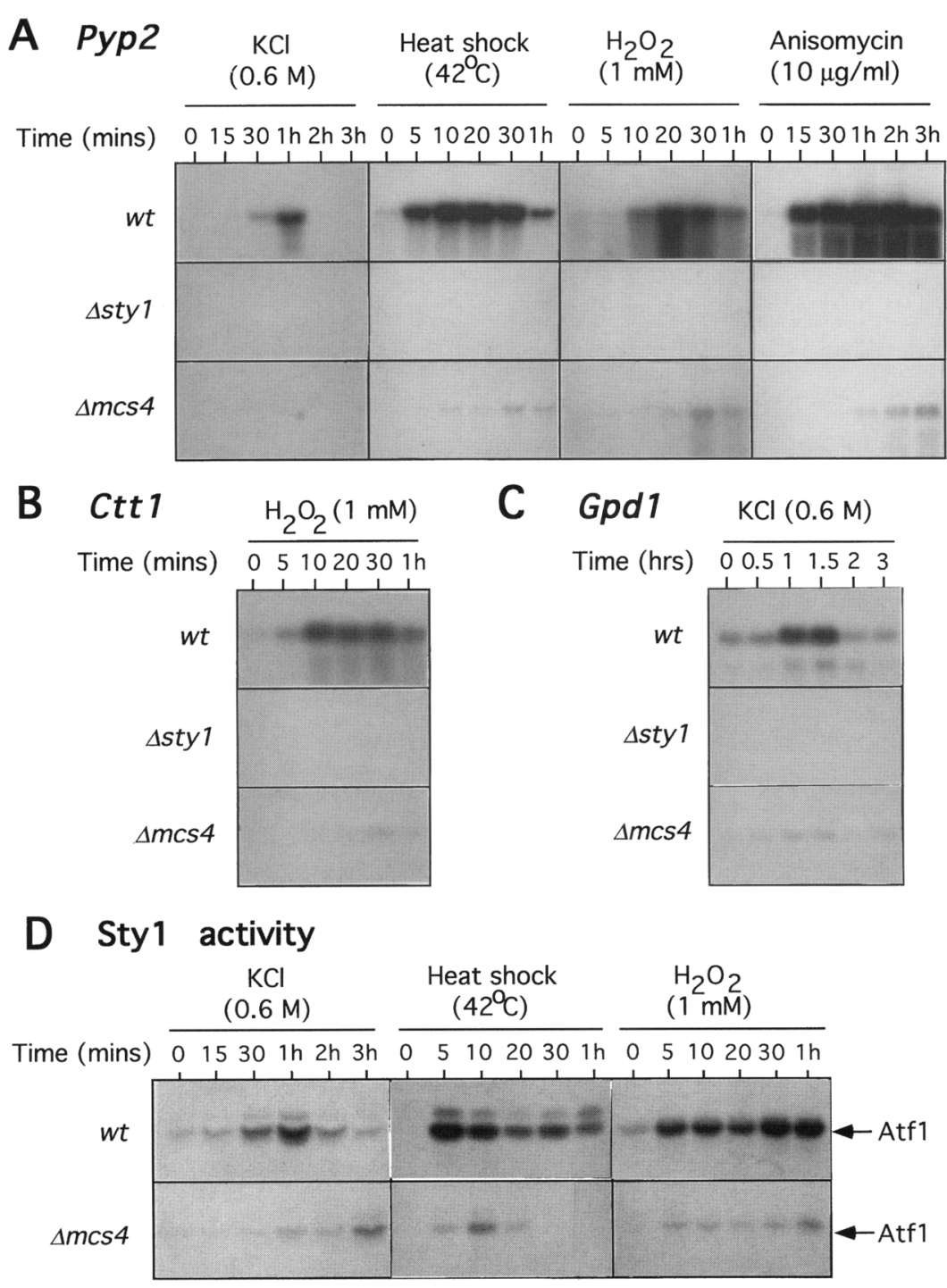

Figure 4. Mcs4 is required for stress-induced gene expression and Styl activation. (A) Expression of the Pyp2 MAP kinase phosphatase is attenuated in cells lacking mcs4. Log-phase cultures growing in YEPD at $30^{\circ} \mathrm{C}$ of wild-type (wt) (PR109), sty1::ura4 (Asty1) (JM 1160), or mcs4::ura4 ( $\Delta$ mcs4) (JM 1354) cells were incubated in the same medium containing $0.6 \mathrm{M}$ $\mathrm{KCl}, 1 \mathrm{mM} \mathrm{H}_{2} \mathrm{O}_{2}$, or shifted to $42^{\circ} \mathrm{C}$ for the times indicated. Total RNA was extracted and equal quantities separated by electrophoresis and probed using DNA specific to the pyp2 gene. Represented blots were probed with the same probe and for the same length of time. Reprobing with both actin- and cdc2-specific probes verified equal loading of RNA. $(B)$ Induction of catalase (ctt1) is attenuated in cells lacking mcs4. An experiment similar to that described in $A$ was performed in which wild-type (wt) (PR109), sty1::ura4 (Asty1) (JM 1160), or mcs4::ura4 (Amcs4) (JM 1354) cells were incubated in medium containing $1 \mathrm{mM} \mathrm{H}_{2} \mathrm{O}_{2}$ for the times indicated. In this experiment total RNA was extracted and probed using DNA specific to the $c t t 1$ gene. $|C|$ Induction of gpd1 is attenuated in cells lacking mcs4. An experiment similar to that described in $A$ was performed in which wild-type (wt) (PR109), sty1::ura4 ( $\Delta$ sty1) (JM 1160), or mcs4::ura4 (Amcs4) (JM 1354) cells were incubated in medium containing $0.6 \mathrm{M}$ $\mathrm{KCl}$ for the times indicated. Total RNA was extracted and probed using DNA specific to the gpd1 gene. $(D)$ Activation of Styl in cells lacking mcs4. Log-phase cultures of either wild-type (wt) (PR109) or mcs4::ura4 (Amcs4) (JM 1354) cells growing in YEPD at $30^{\circ} \mathrm{C}$ were incubated in the same medium containing $0.6 \mathrm{M} \mathrm{KCl}, 1$ $\mathrm{mM} \mathrm{H}_{2} \mathrm{O}_{2}$ or shifted to $42^{\circ} \mathrm{C}$ for the times indicated. Cell extracts were prepared and Styl precipitated with GST-Atf1 prebound to glutathione beads. Precipitates were washed extensively and incubated in the presence of $\left[\gamma^{32} \mathrm{P}\right] \mathrm{ATP}$ for $20 \mathrm{~min}$ at $30^{\circ} \mathrm{C}$. Phosphorylation of Atfl was visualized after SDS-PAGE and autoradiography.
Wakl shares extensive structural homology in the amino-terminal noncatalytic half of the protein to both SSK2 and SSK22 kinases (Fig. 5B). To assess whether wak1 is required for Sty1 MAP kinase pathway function, a chromosomal deletion of the wak1 locus was constructed by replacement of at least $50 \%$ of the wak 1 ORF with the $\mathrm{ura}^{+}$marker (Fig. 5A). Tetrad dissection of asci from heterozygous diploids gave rise to four viable spores on germination that showed a $2: 2$ segregation of uracil auxotrophs to uracil prototrophs, indicating that wak 1 is not an essential gene. Importantly, $\Delta w a k 1$ cells were found to be delayed in the timing of mitotic initiation dividing at $16.5 \pm 1.3 \mu \mathrm{m}$ relative to $14.2 \pm 0.3 \mu \mathrm{m}$ for wild type. As is the case with mcs4, wis1, and sty1, the effect of loss of wak1 activity on cell size at division is greatly enhanced in combination with the $c d c 25-22 \mathrm{mu}-$ tant (Table 1).

To assess whether wak1 is required for stress-induced gene expression or Styl activation, wild-type or $\Delta w a k 1$ cells were grown to log phase and then given a temperature shock. As the results in Figure 6A demonstrate, induction of $p y p 2$ and activation of Sty 1 were dramatically lowered in $\Delta$ wak 1 cells, although some residual induction was observed. Similar results were obtained when the cells were challenged with an osmotic or oxidative stress or anisomycin (data not shown). These results strongly suggest that Wak1 is required for activation of the Styl MAP kinase pathway by directly phosphorylating Wis1. To assess the relationship between Wakl and Mcs4, stress-induced gene expression and activation of the Styl MAP kinase were assessed in double $\Delta$ wak1 $\Delta m c s 4$ mutants. As the results in Figure 6 demonstrate, 
Figure 5. Wak1 kinase is a SSK2 and SSK22 homolog. (A) Restriction map of the Wakl ORF. One-kilobase intervals are marked under the map. A map of the wak $1:$ ura 4 construction is also shown. $(B)$ Sequence comparison of Wak1 protein to the SSK2 and SSK2 MEK kinases. The nucleic acid sequence of the Wak1 gene will appear in the EMBL, GenBank, and DDBJ Nucleotide Sequence Databases under accession no. Y11989.

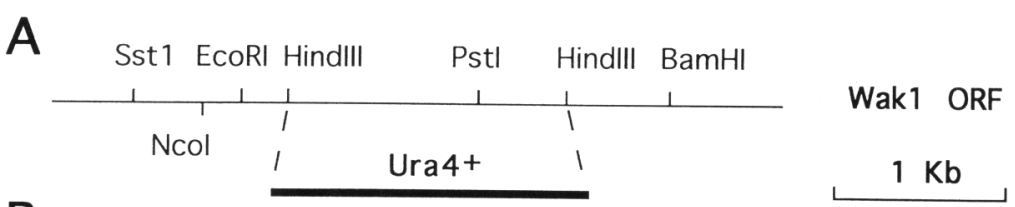

B

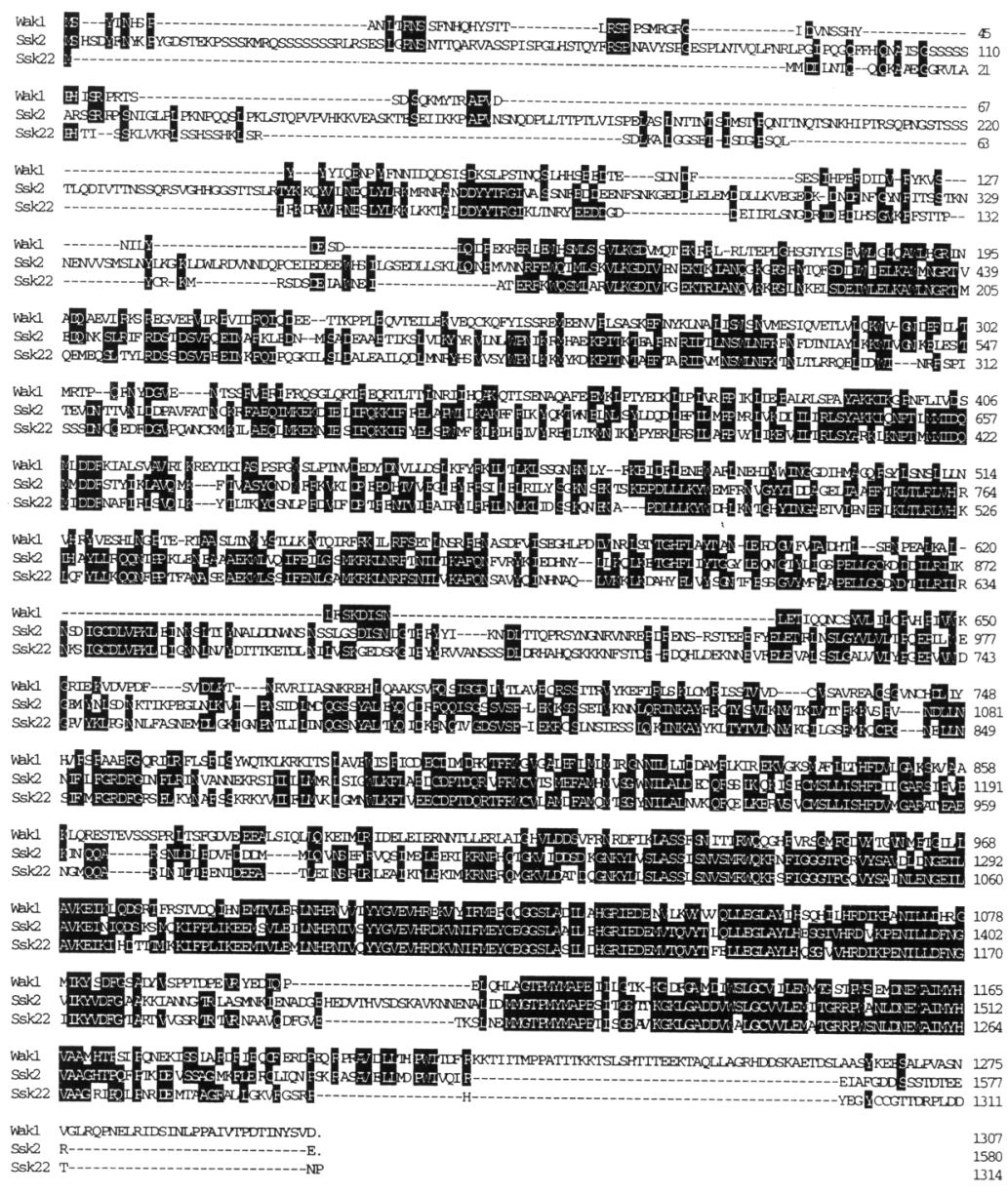

induction of pyp2 and activation of Styl in $\Delta$ wak1 $\Delta m c s 4$ cells was not detectably different from single $\Delta$ wak1 cells alone. These results suggest that Mcs 4 and Wakl lie on the same signal transduction pathway. To test this two separate genetic experiments were performed. First, $\Delta$ wak 1 cdc25-22 cells were transformed with plasmids expressing either wis 1 or mcs 4 genes. At $30^{\circ} \mathrm{C} \Delta w a k 1$ cdc25-22 cells undergo cell cycle arrest, whereas $\Delta$ wak 1 and $c d c 25-22$ single mutants are able to proliferate normally (Fig. 7A). We observe that wis 1 is able to suppress the cell cycle arrest of a $\Delta w a k 1 c d c 25-22$ strain at $30^{\circ} \mathrm{C}$, whereas overexpression of mcs 4 is without effect (Fig. 7A). Hyperactivation of the Styl pathway by massive overexpression of the wis 1 MEK is lethal (Fig. 1). The data in Figure $7 \mathrm{~B}$ indicate that massive overexpression of mcs 4 is also toxic to wild-type cells. This is most likely attributable to hyperactivation of Wak1, because this lethality is suppressed in cells deleted for any of the wak1, wis1, or sty1 genes (Fig. 7B). Together these results suggest that Mcs4 acts upstream of Wak1 to transmit the stress signal to the Styl MAP kinase, although the precise mechanism of action is at present unknown.

Wis 1 MEK is controlled by a Wak1-and Mcs4-independent pathway

The previous results demonstrate that Mcs4 and Wakl are important components of the signal transduction pathway leading to stress-induced activation of Sty1. To assess the role of mcs 4 and wak1 in the response of the cell to environmental stress, wild-type cells or those deleted for the sty1, wis1, wak1, or mcs4 genes were grown on rich medium at $30^{\circ} \mathrm{C}$, on the same medium containing $1.2 \mathrm{M}$ sorbitol, or on the same medium at $37^{\circ} \mathrm{C}$. Whereas $\Delta$ wis 1 and $\Delta$ sty 1 cells were unable to grow at 
A

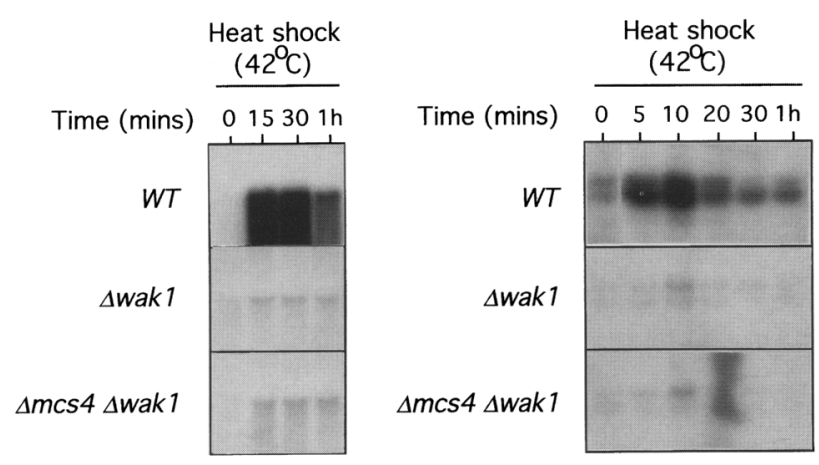

Figure 6. Wak 1 is required for activation of the Styl MAP kinase cascade. (A) Wak1 is required for induction of the Pyp2 MAP kinase phosphatase. Log-phase cultures growing in YEPD at $30^{\circ} \mathrm{C}$ of wild-type (wt) (PR 109), wak1::ura4 (Awak1)

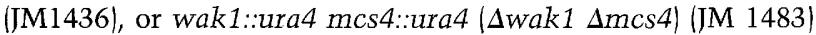
cells were shifted to $42^{\circ} \mathrm{C}$ for the times indicated. Total RNA was extracted and probed using DNA specific to the pyp2 gene. Blots were reprobed with both actin- and $c d c 2$-specific probes for normalization of RNA levels. $(B)$ Wakl is required for activation of Styl. Log-phase cultures of cells as in $A$ were shifted to $42^{\circ} \mathrm{C}$ for the times indicated. Cell extracts were prepared and the Styl MAP kinase isolated by incubation with GST-Atfl and affinity precipitation on glutathione-agarose beads. Precipitates were washed extensively and incubated in the presence of $\left[\gamma^{32} \mathrm{P}\right] \mathrm{ATP}$ for $20 \mathrm{~min}$ at $30^{\circ} \mathrm{C}$. Products were visualized after separation on a $10 \%$ SDS-PAGE gel and autoradiography.

high temperature or under hyperosmolar conditions as observed previously (Millar et al. 1995), $\Delta$ wak1 and $\Delta m c s 4$ cells were still able to form colonies, though not as effectively as wild type (Fig. 8A). These results indicate the existence of a second pathway for activating the Wis 1 MEK by environmental stress that is independent of both the Wak1 and Mcs4 upstream regulators. We note that cells deleted for either mcs 4 or wak 1 are also not as severely delayed in the timing of mitotic initiation as $\Delta$ wis 1 or $\Delta$ sty 1 cells (Table 1; Millar et al. 1995), suggesting that this alternative pathway also contributes to cell cycle control by the Styl MAP kinase pathway.

\section{Mcs4 controls Cdc2 activation by a Sty1-independent pathway}

The previous results suggest that Mcs4 is an important regulator of Styl activity. Because the mcs4-13 mutant was originally identified based on its ability to suppress the premature and lethal mitotic catastrophe caused by hyperactivation of $\mathrm{Cdc} 2$ kinase, we wished to determine whether this phenotype is a result of a reduction in Styl MAP kinase activity (Molz et al. 1989). To assess this the mcs4, sty1, and wis1 genes were independently disrupted in $c d c 2-3 w$ wee $1-50$ cells, and the viability of the cells determined at the permissive temperature of $25^{\circ} \mathrm{C}$ and restrictive temperature of $32^{\circ} \mathrm{C}$. At these temperatures the growth rates of $\Delta s t y 1, \Delta w i s 1$, or $\Delta m c s 4$ cells are not detectably different from wild type (Warbrick and
Fantes 1991; Millar et al. 1995; Shiozaki and Russell 1995; J.B.A. Millar, unpubl.). As the results in Figure 9 demonstrate, loss of either wis1 or sty1 does not prevent cdc2-3w wee 1-50 cells from undergoing a lethal mitotic catastrophe at $32^{\circ} \mathrm{C}$, whereas loss of mcs 4 does, in agreement with previous observations (Molz et al. 1989). These results indicate that Mcs 4 controls the $G_{2} / M$ transition in fission yeast both by regulating Styl MAP kinase activity and by influencing a second Styl-independent pathway required for the correct timing of $\mathrm{Cdc} 2$ kinase activation.

\section{Discussion}

The fission yeast Styl MAP kinase is activated by a wide range of environmental insults, including osmotic stress, oxidative stress, DNA damaging agents, heat shock, and the protein synthesis inhibitor anisomycin. This is similar to the mammalian JNK/SAPK and p38/CSBP1 MAP kinases, but directly contrasts with the budding yeast HOG1 MAP kinase, which is activated only by osmotic stress (Schüller et al. 1994). We have identified two upstream regulators of the Styl MAP kinase cascade as the Mcs4 response regulator and the Wak1 MEK kinase. Mcs4 is both structurally and functionally related to the SSK1 gene product of budding yeast, which is a component of a phospho-relay system that regulates the HOG1 MAP kinase cascade in response to osmotic stress (Maeda et al. 1994, 1995; Posas et al. 1996). Activation of HOG 1 is caused by inactivation of SLN1 and subsequent dephosphorylation of SSK1 on aspartate 544. In a similar manner we have shown that phosphorylation of Mcs 4 on the equivalent aspartate residue is not necessary for Mcs4 activity. In budding yeast SSK1 is thought to act directly upstream of the MEK kinases SSK2 and SSK22. We have identified a homolog of the SSK2 and SSK22 MEK kinases in fission yeast, Wakl, that is required for Styl activation in response to multiple stresses. Although the precise relationship between Mcs4 and Wakl is at present unclear, we show that $\Delta$ wak1 cells are epistatic to changes in mcs 4 expression, suggesting that Wakl transmits the stress signal from Mcs4 to the Wis1 MEK and Sty1 MAP kinase (Fig. 10). These results indicate that a response regulator protein acts as part of a multistress sensor in fission yeast to control the activity of the Styl MAP kinase cascade.

In contrast to SSK1, Mcs4 is required for activation of the Styl MAP kinase in response to multiple stresses including osmotic stress, heat shock, oxidative stress, the superoxide generator menadione, and the protein synthesis inhibitor anisomycin. One might predict from this that the putative histidine kinase that controls Mcs4 in fission yeast must be regulated by multiple stresses and is not simply an osmosensor. An alternative explanation for this difference is that multiple histidine kinases for Mcs4 exist in fission yeast, each of which is responsible for sensing a distinct cellular stress. Intriguingly, using a PCR-based approach, recently we have isolated two transmembrane histidine kinases in fission yeast, called Mak1 and Mak2, suggesting this latter pos- 
Shieh et al.

Figure 7. Mcs4 acts upstream of the Wak1 MEK kinase. (A) Wak1 is epistatic to mes4. $\Delta$ wak1::ura4 cdc25-22 cells (JM1469) were transformed with a control plasmid pREP41 (pControl), pREP41-wis1 (pWis1), or pREP41-mcs4 (pMcs4) behind the thiamine-repressible nmt1 promoter. Transformants were grown and streaked on minimal medium lacking thiamine and leucine and cultured for 3 days at temperatures shown. $(B)$ Lethal overexpression of mcs 4 is suppressed by loss of wak1. Wild-type (WT) (PR109), sty1::ura4

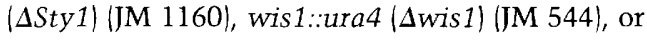
wak1::ura4 (Awak1) (JM1436) cells were transformed with pREP1-mcs4. Transformants were selected on minimal medium lacking leucine containing $10 \mu \mathrm{M}$ thiamine and then streaked onto the same medium (+ thiamine) or the same medium lacking thiamine (-thiamine) and growth of the cells monitored after 5 days at $30^{\circ} \mathrm{C}$.

A

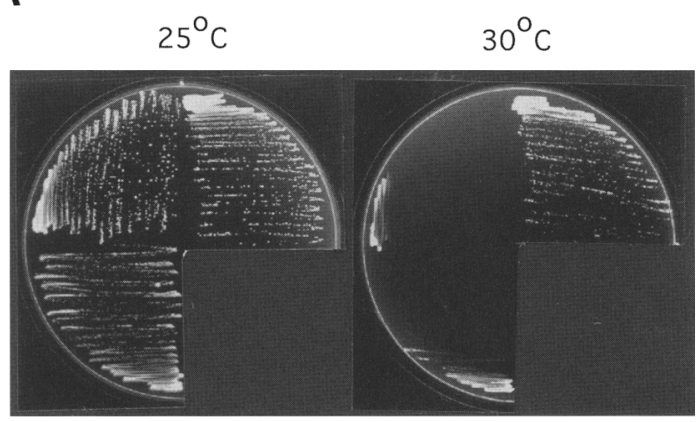

uwak1 cdc25-22

B
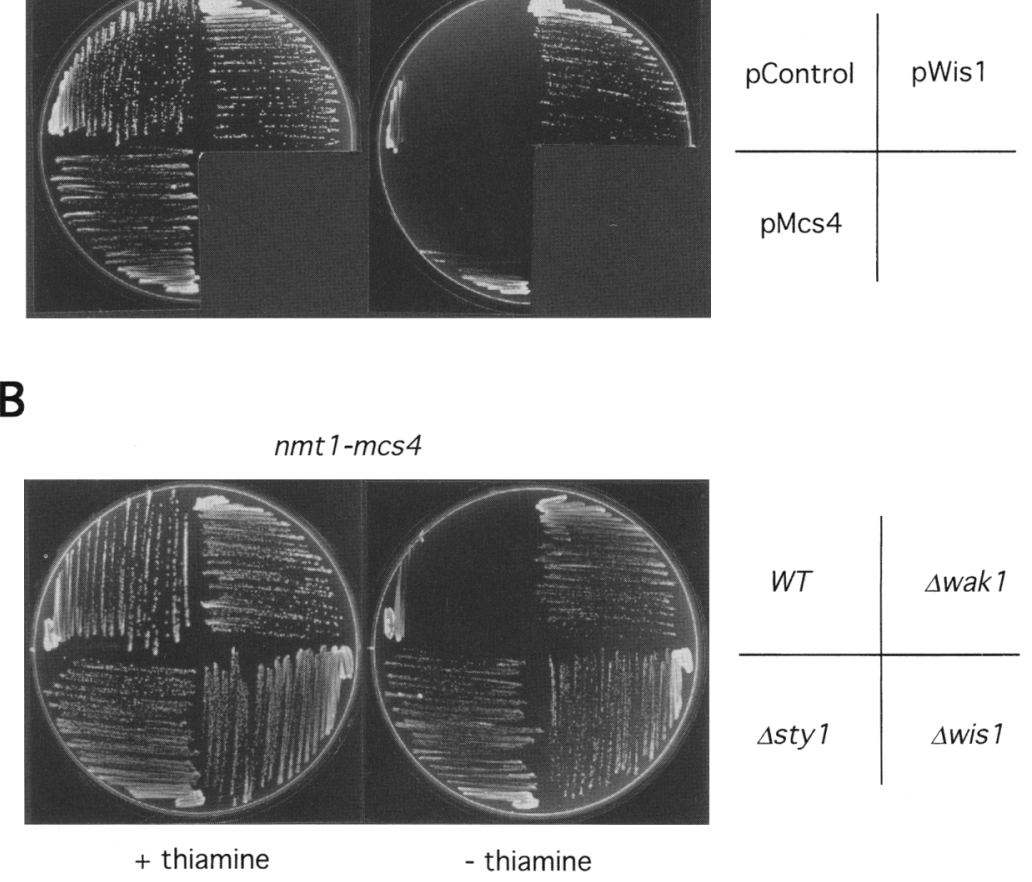

sibility may be the case (K. Makino and J. Millar, unpubl.). In this light we note that the time course of Styl activation by hyperosmolarity or anisomycin is considerably slower than that observed with heat shock or oxidative stress. This could be a result of either differential utilization of histidine kinases or slower generation of a common second messenger. Currently we are trying to distinguish between these possibilities. It is important to point out that we have not provided formal proof that Mcs4 becomes dephosphorylated on aspartate 412 in response to multiple stresses, and as such the mechanism by which cellular stress is sensed in fission yeast is still unclear.

The Styl MAP kinase and mammalian SAPK/INK and p38 MAP kinase are stimulated by a remarkably similar range of environmental stimuli. This data would imply that a two-component system may act upstream of the SAPK/JNK and p38/CSBP1 pathways in mammalian cells. This possibility is strengthened by the recent finding that a direct downstream target of Styl is the Atfl transcription factor, a structural homolog of human ATF2, which binds and is activated by the SAPKaII/ INK2 MAP kinase (Gupta et al. 1995; Shiozaki and Russell 1996; Wilkinson et al. 1996). However, no mammalian homologs of the Mcs4 response regulator or Mak1 and Mak2 histidine kinases have yet been identified. Several upstream regulators of the mammalian the SAPK/JNK and p38/CSBP1 MAP kinases have been cloned, including MEKs that are responsible for either p38 activation (MKK3 and MKK6) or JNK/SAPK activa-

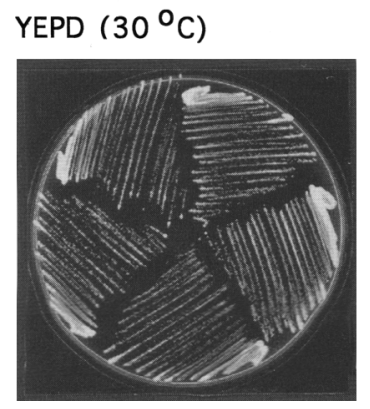

YEPD + 1.2 M Sorb.
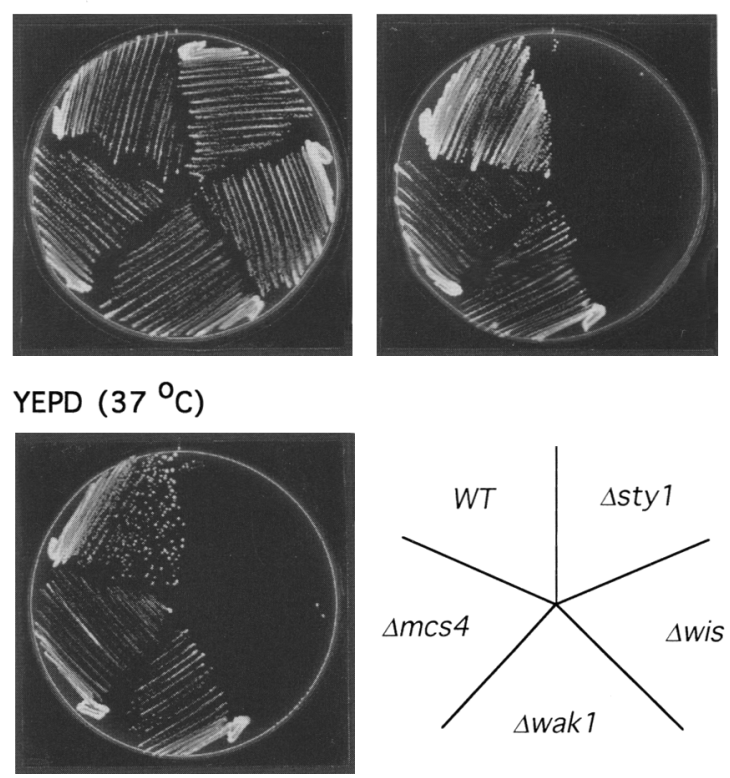

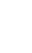


$25^{\circ} \mathrm{C}$

$$
32^{\circ} \mathrm{C}
$$

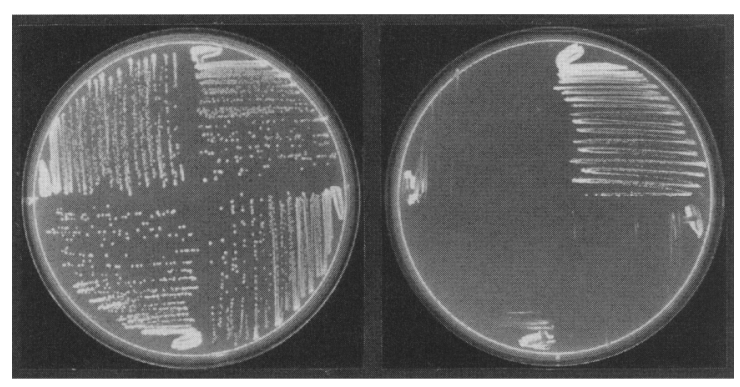

cdc2-3w wee $1-50$

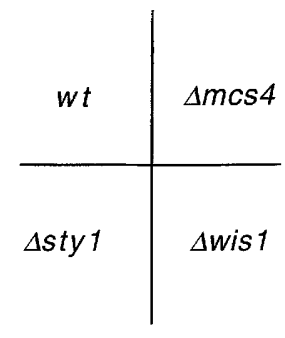

Figure 9. Mcs4 controls mitotic initiation by a Sty1-independent mechanism. Cdc2-3w wee1-50 (wt), cdc2-3w wee1-50 mcs4::ura4 (4mcs4), cdc2-

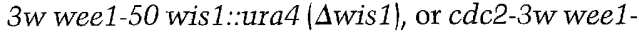
50 sty $1:$ ura4 $\mid \Delta$ styl| cells were grown on YEPD at $25^{\circ} \mathrm{C}$ and then streaked on the same medium either at $25^{\circ} \mathrm{C}$ or $32^{\circ} \mathrm{C}$ and growth of colonies examined after 6 days. tion (MKK4) (Sanchez et al. 1994; Yan et al. 1994; Dérijard et al. 1995; Lin et al. 1995; Raingeaud et al. 1996). MKK4 is activated by overexpression of a number of MEK kinases, including MEKK1, TAK1, MUK, SPRK/ MLK3, and Tp12/Cot1, perhaps in a tissue-specific manner (Yan et al. 1994; Yamaguchi et al. 1995; Hirai et al. 1996; Rana et al. 1996; Salmeron et al. 1996). In addition, a number of upstream regulators of MEKK1 have been proposed, also based on transient transfection studies in mammalian cells, including the STE20-related protein kinases PAK-1, PAK-3, germinal center kinase (GCK), and HPK1 (Bagrodia et al. 1995; Pombo et al. 1995; Hu et al. 1996; Zhang et al. 1996). Some of the PAKs bind and are activated by members of the Rho family of GTPases, Rac1 and Cdc42, constitutively activated versions of which can also stimulate the JNK/SAPK and p38 pathways (Bagrodia et al. 1995; Coso et al. 1995; Minden et al. 1995). These latter results are somewhat curious because no role for the STE20-like kinases or Cdc42 proteins has yet been found in signal transmission to the budding yeast HOG1 or fission yeast Styl MAP kinases. It should be noted, however, that the mammalian stress-activated MAP kinases are also stimulated by receptor occupancy at the plasma membrane by the proinflammatory cytokines [tumor neurosis factor (TNF $\alpha$ ) and IL-1], bacterial lipopolysaccharide (LPS), certain G-protein coupled receptors, and the lymphocyte costimulatory receptors CD28 and CD40 (Fresney et al. 1994; Han et al. 1994; Sakata et al. 1994; Sluss et al. 1994; Su et al. 1994; Raingeaud et al. 1995). It is possible that distinct upstream regulators may regulate activation of the mammalian SAPK/JNK and p38/CSBP1 MAP kinases in response to different stimuli.

Importantly, the HOG1 MAP kinase is activated by hyperosmolarity in cells lacking either the SSK1 or the SSK2 and SSK22 MEK kinases (Maeda et al. 1995). We provide evidence in this paper that alternative stressinducible pathways also exist for activating the Wis1 MEK in fission yeast that are independent of the Mcs4 response regulator and Wak1 MEK kinase (Fig. 10). First, stress-induced expression of the $p y p 2$, ctt1, and gpd1 genes is observed in $\Delta m c s 4$ and $\Delta w a k 1$ cells, albeit to a greatly reduced degree, whereas all induction is abolished in either $\Delta$ wis 1 or $\Delta s t y 1$ cells. Second, we consistently observe inducible activation of Styl MAP kinase in $\Delta m c s 4$ and $\Delta w a k 1$ cells, whereas all activation is abolished in the absence of Wis 1 . This is consistent with the observation that both the Wisl and Styl kinases are ab-

\begin{tabular}{l} 
Osmotic Stress \\
Heat Shock \\
Oxidative stress \\
Anisomycin \\
\hline
\end{tabular}

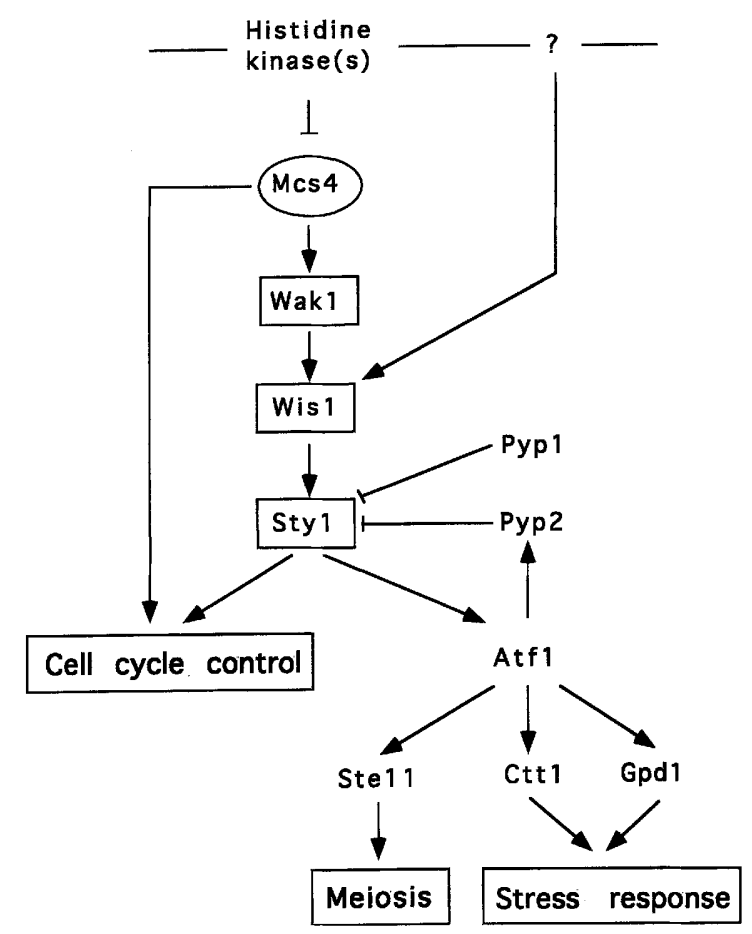

Figure 10. A model for control of the fission yeast stress-activated Sty 1 MAP kinase cascade and cell cycle by the Mcs4 response regulator. We propose that multiple stresses are sensed by an as-yet-defined histidine kinase. This leads to dephosphorylation of Mcs4 on a conserved aspartate residue D412, which relieves inhibition of the Wakl MEK kinase, perhaps by direct binding to Wak1. Activation of Wakl leads to phosphorylation of Wis1, which in turn leads to phosphorylation and activation of the Sty1 MAP kinase. We propose that Mcs4 influences cell cycle progression by pathways both dependent and independent on Styl. 
Table 2. Strains used in this study

\begin{tabular}{|c|c|c|}
\hline Strain no. & Genotype & Reference/source \\
\hline PR 109 & leu1-32 ura4-D18 $\mathrm{h}^{-}$ & P. Russell \\
\hline JM 1351 & leu1-32 ura4-D18 ade6-M210 his7-366 cdc25-22 $\mathrm{h}^{+}$ & this study \\
\hline JM 1144 & leu1-32 ura4-D18 sty $1-1 \mathrm{~h}^{-}$ & Millar et al. (1995) \\
\hline JM 1160 & leu1-32 ura4-D18 ade6-216 sty1::ura4 $\mathrm{h}^{-}$ & Millar et al. (1995) \\
\hline JM 544 & leu1-32 ura4-D18 wis1::ura4 $h^{-}$ & Millar et al. (1995) \\
\hline SP 890 & $\operatorname{mcs} 4-13 h^{-}$ & Molz and Beach (1989) \\
\hline IM 1303 & ura4-D18 mcs4-13 cdc25-22 $\mathrm{h}^{-}$ & this study \\
\hline JM 1347 & leu1-32 ura4-D18 ade6-M210 his $7-366 \mathrm{mcs} 4-13 \mathrm{~h}^{+}$ & this study \\
\hline JM 1354 & leu1-32 ura4-D18 ade6-M210 his7-366 mcs4::ura4 $\mathrm{h}^{+}$ & this study \\
\hline JM 1468 & leu1-32 ura4-D18 ade6-M210 his7-366 mcs $4:$ his $7 \mathrm{~h}^{+}$ & this study \\
\hline $\mathrm{JM} 1436$ & leu1-32 ura4-D18 ade6-M210 his7-366 wak1::ura4 $h^{+}$ & this study \\
\hline JM 1469 & leu1-32 ura4-D18 ade6-M210 his7-366 wak1:ura4 cdc25-22 $\mathrm{h}^{+}$ & this study \\
\hline JM 1483 & leu1-32 ura4-D18 ade6-M210 his7-366 wak1::ura4 mcs4::his7 $\mathrm{h}^{+}$ & this study \\
\hline PR 12 & leu1-32 ura4-D18 cdc2-3w wee1-50 $\mathrm{h}^{-}$ & P. Russell \\
\hline JM 1367 & leu1-32 ura4-D18 ade6-M210 sty1::ura4 cdc2-3w wee1-50 $\mathrm{h}^{+}$ & this study \\
\hline JM 553 & leu1-32 ura4-D18 wis $1:$ ura 4 cdc2-3w wee $1-50 \mathrm{~h}^{-}$ & this study \\
\hline JM 1480 & leu1-32 ura4-D18 ade6-M210 mcs4::ura4 cdc2-3w wee1-50 $\mathrm{h}^{+}$ & this study \\
\hline
\end{tabular}

solutely required for growth under conditions of environmental stress, whereas Mcs4 and Wak1 cells are not. The nature of this alternative pathway is not known but may involve a distinct MEK kinase from Wakl or a homolog of the $\mathrm{SH} 3$ domain containing protein, SHO1, which is thought to act as an alternative osmosensor in budding yeast by binding to the amino terminus of the PBS2/ HOG4 MEK (Maeda et al. 1995). Notably, whereas the Wis1-Styl-Atfl pathway is also required for viability in stationary phase, sexual conjugation, and meiotic progression (Warbrick and Fantes 1991; Takeda et al. 1995; Kato et al. 1996; Wilkinson et al. 1996), cells lacking either the mcs 4 or wak 1 genes only have a limited or undetectable defect in these processes (J.-C. Shieh and J.B.A. Millar, unpubl.). Because $\Delta m c s 4$ and $\Delta$ wak1 cells are shorter at division than $\Delta$ wis 1 or $\Delta s t y 1$ cells, we presume this alternative pathway also controls the timing of mitotic initiation.

The Styl MAP kinase was initially identified based on its effects on cell size at division (Millar et al. 1995; Shiozaki and Russell 1995). Because the timing of mitotic initiation requires attainment of a critical cell size before Cdc 2 is activated, these results imply that Styl directly or indirectly influences the activity of the Cdc2 kinase. At present the mechanism underlying this control is unknown, but is likely to be independent of both the Weel tyrosine kinase and Cdc 25 protein phosphatase, because wis 1 and sty 1 mutations can reverse the suppression of $c d c 25-22$ temperature-sensitive mutants by wee1 inactivation (Warbrick and Fantes 1991; J.B.A. Millar, unpubl.). Notably the mcs 4 mutant, which was isolated by its ability to suppress the lethal hyperactivation of the central mitotic regulator $\mathrm{Cdc} 2$, also displays this phenotype (Molz et al. 1989; Warbrick and Fantes 1992). These results suggest that Mcs 4 controls the timing of mitotic initation by effecting Styl activity. Nevertheless loss of either wis 1 or sty 1 is not sufficient to suppress mitotic catastrophe caused by hyperactivation of $\mathrm{Cdc} 2$, demonstrating that Mcs 4 controls the timing of $\mathrm{Cdc} 2$ kinase activation by an additional Styl-independent pathway (Fig. 10). Intriguingly the budding yeast MCM1 transcription factor, which is required for the periodic expression of a number of genes at the $G_{2} / M$ transition, recently has been shown to be regulated by the SLN1 histidine kinase in a HOG1-independent manner (Yu et al. 1995). Whether a similar factor is under the control of Mcs4 in fission yeast is currently under investigation. In conclusion, these data illustrate an important role for a conserved two-component system in the coordination of cell cycle progression with the cellular response to environmental stress.

\section{Materials and methods}

\section{Media and general techniques}

Media and genetic methods for studying fission yeast have been reviewed recently (Moreno et al. 1991). General DNA methods were performed using standard techniques (Sambrook et al. 1989). Cell-length measurements were made using log-phase cells with a Nikon filar eyepiece drum micrometer at $1200 \times$ magnification. Transformations were regularly performed by lithium acetate method (Moreno et al. 1991) or by electroporation (Prentice 1991) using a Bio-Rad Gene Pulser. Strains used in this study are listed in Table 2.

\section{Overexpression of wis1}

The wis1 ORF was excised from pREP42-wis1 (HA-6His) (Millar et al. 1995) by digestion with with NdeI and NotI and ligated into the NdeI and NotI sites of pREP1 (HA-6His) (Maundrell 1993; J.B.A. Millar, unpubl.) bearing the LEU2 selectable marker to form pREP1-wis1 (HA-6His). This plasmid was used to transform strains bearing the leu1-32 mutation and leucine prototrophs selected. The phenotype of overexpression was determined after at least $48 \mathrm{hr}$ growth in the absence of thiamine.

Isolation of the mcs4 genomic clone

A genomic library, pURB1 (Barbet et al. 1992), was introduced into a mcs4-D18 cdc25-22 ura4-D18 $\mathrm{h}^{-}$strain by electropora- 
tion and plated on medium lacking uracil. A total of 55,000 transformants were screened. Transformants were replica plated twice to $30^{\circ} \mathrm{C}$ and 53 complementing colonies identified. DNA from these colonies were isolated by transformation into Escherichia coli. Plasmids encoding $c d c 25$, nim1, or wis1 were identified by Southern blot analysis. The eight remaining plasmids were related by restriction map. pURB1-Mcs4-1 contained a 3.25-kb insert (isolated five times); pURB1-Mcs4-2 (isolated twice) contained a $3.1-\mathrm{kb}$ insert; and pURB1-Mcs4-3 (isolated once) contained a 5.6-kb insert. pMcs4-1 was used for further analysis.

\section{Localization and sequencing of the mcs4 gene}

Simultaneous localization and sequencing was performed by transposon mutagenesis of the pURB1-Mcs4-1 genomic clone using TnHIS3 as described previously (Sedgewick and Morgan 1994). Complementing activity was tested by the transformation of transposed DNA into a mcs4-13 cdc25-22 ura4-D18 strain, which was assayed for growth at $30^{\circ} \mathrm{C}$. Dideoxy sequencing was performed using a $\mathrm{T} 7$ sequencing kit from Pharmacia using primers to the $5^{\prime}$ and $3^{\prime}$ ends of the transposon that were described previously.

\section{Disruption of Mcs4}

pCRII-Ura4 (J.B.A. Millar, unpubl.) was digested with XhoI and $B a m H I$ and the resulting $1.6-\mathrm{kb} \mathrm{Ura4}^{+}$fragment ligated into pURB1-Mcs4-1 that had been digested previously with BgIII and Xhol to form pURB1-Mcs4::ura4(BX). The fragment removed contains $>50 \%$ of the Mcs4 ORF. Plasmid pURB1-Mcs4::ura4(BX) was linearized with SstI and transformed into a leu1-32/leu1-32 ade6-210/ade6-216 ura4-D18/ura4-D18 $\mathrm{h}^{-} / \mathrm{h}^{+}$strain. Stable integrants were selected on medium lacking uracil and genomic DNA subjected to Southern blot hybridization using an mcs4specific probe. Colonies bearing a disruption of mcs 4 were plated onto minimal medium containing adenine to induce sporulation. The resulting asci were used for tetrad dissection and DNA from the resulting haploid uracil prototrophs isolated to confirm disruption of mcs 4 by genomic Southern blot analysis.

\section{Overexpression of the fission yeast mcs4 and budding yeast} SSK1 and SKN7 genes

The entire mcs 4 ORF was amplified from pURB1-Mcs4-1 by PCR by use of the $5^{\prime}$ oligonucleotide CATAAGGATCCACATATGCGCATTTGGTTTAAAAAAG (Mcs4-N1) containg a $B a m H I$ and Ndel site (italicized) and the $3^{\prime}$ oligonucleotide CAATAGGATCCGAATTCTGCAGTCATCGACCGCGAAAACGGCA (Mcs4-C1) containing BamHI, EcoRI, and PstI sites (italicized). The resulting $1.58-\mathrm{kb}$ product was digested with $\mathrm{NdeI}$ and $\mathrm{BamHI}$ and cloned into the NdeI and BamHI sites of pREP4l bearing an attenuated version of the nmt1 promoter (Basi et al. 1993) to form pREP41-Mcs4. The same fragment was cloned into the NdeI and BamHI sites of pREP1 to form pREP1Mcs4.

The entire SSK1 gene was amplified from $S$. cerevisiae cDNA using the $5^{\prime}$ oligonucleotide CTGCTGTAAATCATATGCGAATCGATTTTGGGG (SSK1-1) and the 3' oligonucleotide ACATTCTATCATATGGTCCTCTACACGGTACAAC (SSK12), both containing a NdeI site (italicized), digested with $N d e$ I and cloned into the NdeI site of pREP41 to form pREP41-SSK1. In a similar manner the entire SKN7 response regulator protein was amplified by use of the 5 ' oligonucleotide ACTGAAGGGGATCCAATATTGAACGAAAAG (SKN7-1) and the $3^{\prime}$ oligo- nucleotide GCTTACTTTTGGGATCCACTATGAGC (SKN72), both containing a BamHI site (italicized), digested with BamHI and cloned into the BamHI site of pREP41 to form pREP41-SKN7.

\section{Mutation of putative phospho-acceptor residue in Mcs4}

Aspartic acid (D) 412 in the Mcs4 protein was mutated to asparagine $(\mathrm{N})$ by mutagenic PCR amplification of the gene in two parts by use of the oligonucleotides Mcs4-N1 (see above) in combination with the $3^{\prime}$ mutagenic oligonucleotide CGTGGGAAGTTGGATGTTCATTAGAATCAAGTG (Mcs4-DN3) and the 5' mutageinc oligonucleotide CACTTGATTCTAATGAACATCCAACTTCCCACG (Mcs4-DN5) in combination with the $3^{\prime}$ oligonucleotide $\mathrm{Mcs} 4-\mathrm{Cl}$ (see above). The mutated base is underlined. Products from each reaction were then combined and a second round of amplification performed by use of the oligonucleotides Mcs4-N1 and Mcs4-C1. The resulting $1.57-\mathrm{kb}$ product was cloned to pREP41 as described above to form pREP41-Mcs4(D412N). A similar strategy was used to mutate residue 412 to glutamic acid (E) by use of the mutagenic oligonucleotides CGTGGGAAGTTGGATCETCCATTAGAATCAAGTG (Mcs4-DE3) and CACTTGATTCTAATGGAGATCCAACTTCCCACG (Mcs4-DE5) to form pREP41-Mcs4(D412E). Both mutations were confirmed by DNA sequencing.

\section{Isolation and disruption of Wak 1}

A $4.2-\mathrm{kb}$ clone of wak 1 was isolated from the fission yeast cosmid ICRFc 60 G 109 by use of the $5^{\prime}$ oligonucleotide ATAGAGCGGCCGCAGATCTTATGGGGCTAGAGCATACT bearing $B g I I I$ and NotI sites (shown italicized) that hybridized to sequences in the promoter region of wak 1 and the $3^{\prime}$ oligonucleotide CATAGGTACCAGATCTTTAGTCAACACTATAGTTTATTGTG bearing BgIII and KpnI sites (shown italicized) that hybridized to sequence around the termination codon. The fragment was digested with NotI and KpnI and cloned into the NotI and KpnI sites of pBSSK to form pBSSK-Wakl. pBSSK-Wak1 was digested with HindIII to release $1.57 \mathrm{~kb}$ of internal Wak1 ORF sequences and the $\mathrm{ura}^{+}$gene ligated into these sites after digestion of pREP42 with HindIII to form pBSSK-Wak1::ura4. pBSSK-Wak1::ura4 was linearized with $B g I I I$ and transformed into a leu1-32/leu1-32 ade6-210/ade6-216 ura4-D18/ura4-D18 $h^{-} / h^{+}$strain. Stable integrants were selected on medium lacking uracil and genomic DNA subjected to Southern blot hybridization by use of a wak1-specific probe. Colonies bearing a disrupted allele of wak 1 were plated onto minimal medium containing adenine to induce sporulation. The resulting asci were used for tetrad dissection and the resulting haploid uracil prototrophs were confirmed to bear a disrupted copy of wak1 by genomic Southern blot analysis. A wak $1:$ :LEU2 strain was constructed by a similar strategy.

\section{Assay of endogenous Sty1 kinase activity}

Endogenous Styl kinase was precipitated from cell extracts and assayed for kinase activity using a GST-Atfl fusion protein bearing a fragment of Atf1-containing residues (81-194) that contains both the binding domain for Styl and three consensus Styl phosphorylation sites (Wilkinson et al. 1996; M. Samuels and $\mathrm{N}$. Jones, unpubl.). Cells were lysed into lysis buffer $10.5 \%$ NP-40, $0.5 \%$ Na-deoxycholate, $50 \mathrm{~mm} \mathrm{NaF}, 10 \%$ glycerol, $2 \mathrm{~mm}$ $\mathrm{Na}$-orthovanadate, $10 \mathrm{mM} \beta$-mercaptoethanol, $10 \mu \mathrm{g} / \mathrm{ml}$ of aprotonin, $10 \mu \mathrm{g} / \mathrm{ml}$ of benzamidine, $2 \mathrm{mM}$ PMSF, $10 \mu \mathrm{g} / \mathrm{ml}$ of pepstatin $\mathrm{A}, 10 \mu \mathrm{g} / \mathrm{ml}$ of leupeptin, $50 \mathrm{~mm}$ Tris- $\mathrm{HCl}$ at $\mathrm{pH} 7.4)$ and the Sty1 protein isolated by affinity precipitation on GST-Atf1 
protein prebound to glutathione beads. Protein concentration in cell extracts were measured by Lowry and adjusted prior to precipitation. Precipitated proteins were washed three times with lysis buffer containing $0.5 \mathrm{M} \mathrm{NaCl}$, washed once with kinase assay buffer without ATP, and then incubated in kinase assay buffer containing $50 \mathrm{~mm}$ HEPES at $\mathrm{pH} 7.4,10 \mathrm{mM} \mathrm{MgCl}, 10 \mathrm{~mm}$ $\mathrm{MnCl}_{2}, 10 \mathrm{~mm}$ EGTA, $10 \mathrm{~mm} \beta$-mercaptoethanol, $0.2 \mu \mathrm{Ci} / \mathrm{ml}$ of $\left[\gamma^{32} \mathrm{P}\right]$ ATP for $20 \mathrm{~min}$ at $30^{\circ} \mathrm{C}$. Reactions were terminated by the addition of SDS-sample buffer and the products separated by SDS-PAGE. Phosphorylation of Atfl was determined by autoradiography.

\section{DNA and RNA isolation and hybridization}

$S$. pombe cells were cultured in YEA medium $10.5 \%$ yeast extract, $3 \%$ glucose, $50 \mathrm{mg} /$ liter of adenine) to stationary phase. Chromosomal DNA isolated from a $10-\mathrm{ml}$ culture was dissolved in $25 \mu \mathrm{l}$ of $10 \mathrm{~mm}$ Tris, $1 \mathrm{~mm}$ EDTA (TE), of which one-fifth was digested and subjected to electrophoresis and Southern blot hybridization. To isolate RNA, S. pombe cells were cultured in YEPD to exponentially growing phase. Ten micrograms of total RNA was isolated and resolved by agarose gel electrophoresis and transferred to nitrocellulose for hybridization. Probes for $p y p 2$, gpd1, and ctt1 were as described previously (Wilkinson et al. 1996). Equal loading of gels was verified by reprobing with act1, cdc2, wis1, or sty1 cDNAs.

\section{Acknowledgments}

The authors thank Dr. Lee Johnston, Dr. Nic Bouquin, and other members of the Division of Yeast Genetics for helpful advice, discussions, and critical reading of the manuscript. The authors thank Dr. D. Beach (Cold Spring Harbor Laboratory), Dr. P. Russell (The Scripps Research Institute, San Diego, CA), and Dr. D. Hughes (Chester Beatty Laboratories, London, UK) for strains. This research was supported by the Medical Research Council.

The publication costs of this article were defrayed in part by payment of page charges. This article must therefore be hereby marked "advertisement" in accordance with 18 USC section 1734 solely to indicate this fact.

\section{References}

Bagrodia, S., B. Dérijard, R.J. Davis, and R. Cerione. 1995. Cdc42 and PAK-mediated signalling leads to INK and p38 MAP kinase activation. J. Biol. Chem. 270: 27995-27998.

Barbet, N., W.J. Muriel, and A.M. Carr. 1992. Versatile shuttle vectors and genomic libraries for use with Schizosaccharomyces pombe. Gene 114: 59-66.

Basi, G., E. Schmid, and K. Maundrell. 1993. TATA box mutations in the Schizosaccharomyces pombe nmt1 promoter affect transcriptional efficiency but not the transcription start point or thiamine repressibility. Gene 123: 131-136.

Brewster, J.L., T. de Valoir, N.D. Dwyer, E. Winter, and M.C. Gustin. 1993. An osmosensing signal transduction pathway in yeast. Science 259: 1760-1763.

Brown, J.L., S. North, and H. Bussey. 1993. SKN7, a yeast multicopy suppressor of a mutation affecting cell wall $\beta$-glucan assembly, encodes a product with domains homologous to prokaryotic two-component regulators and to heat shock transcription factors. J. Bacteriol. 175: 6908-6915.

Buck, V., P. Russell, and J.B.A. Millar. 1996. Identification of a cdk-activating kinase in fission yeast. EMBO J. 14: 61736183.

Chang, C., S.F. Kwok, A.B. Bleeker, and E.M. Meyerowitz. 1993.
Arabadopsis ethylene-response gene ETR1: Similarity of product to two-component regulators. Science 262: 539-544.

Correa-Bordes, J. and P. Nurse. 1995. p2 $5^{\mathrm{ruml} 1}$ orders S phase and mitosis by acting as an inhibitor of the p34 ${ }^{\mathrm{cdc} 2}$ mitotic kinase. Cell 83: 1001-1009.

Coso, O.A., J.-C. Chiariello, J.-C. Yu, H. Teramoto, P. Crespo, N. Xu, T. Miki, and J.S. Gutkind. 1995. The small GTPbinding proteins Rac1 and $\mathrm{Cdc} 42$ regulate the activity of the JNK/SAPK signalling pathway. Cell 81: 1137-1146.

Damagnez, V., T.P. Mäkelä, and G. Cottarel. 1996. Schizosaccharomyces pombe Mop1-Mcs2 is related to mammalian CAK. EMBO J. 14: 6164-6172.

Degols, G., K. Shiozaki, and P. Russell. 1996. Activation and regulation of the Spc1 stress-activated protein kinase in Schizosaccharomyces pombe. Mol. Cell. Biol. 16:28702877.

Dérijard, B., M. Hibi, I.-H. Wu, T. Barrett, B. Su, T. Deng, M. Karin, and R.J. Davis. 1994. JNK1: A protein kinase stimulated by UV light and Ha-Ras that binds and phosphorylates the c-jun activation domain. Cell 76: 1025-1037.

Dérijard, B., J. Raingeaud, T. Barrett, I.-H. Wu, J. Han, R.J. Ulevitch, and R.J. Davis. 1995. Independent human MAP kinase signal transduction pathways defined by MEK and MKK isoforms. Science 267: 682-685.

Freshney, N.W., L. Rawlinson, F. Guesdon, E. Jones, S. Cowley, J. Hsuan, and J. Saklatvala. 1994. Interleukin-1 activates a novel protein kinase cascade that results in the phosphorylation of hsp27. Cell 78: 1039-1049.

Galcheva-Gargova, Z., B. Dérijard, I.-H. Wu, and R.J. Davis. 1994. An osmosensing signal transduction pathway in mammalian cells. Science 265: 806-808.

Gupta, S., D. Campbell, B. Derijard, and R.J. Davies. 1995. Transcription factor ATF2 regulation by the INK signal transduction pathway. Science 267: 389-393.

Han, J., J.-D. Lee, L. Bibbs, and R.J. Ulevitch. 1994. A MAP kinase targeted by endotoxin and hyperosmolarity in mammalian cells. Science 265: 808-811.

Hirai, S.-I., M. Izawa, S.-I. Osada, G. Spyrou, and S. Ohno. 1996. Activation of the JNK signalling pathway by distantly related protein kinases, MEKK and MUK. Oncogene 12: 641650.

Hu, M.C.-T., W.R. Qiu, X. Wang, C. Meyer, and T.-H. Tan. 1996. Human HPK1, a novel human hematopoietic progenitor kinase that activates the JNK/SAPK kinase cascade. Genes \& Dev. 10: 2251-2264.

Kato, T., K. Okazaki, H. Murakami, S. Stettler, P. Fantes, and H. Okayama. 1996. Stress signal, mediated by a HOG1-like MAP kinase, controls sexual development in fission yeast. FEBS Lett. 378: 207-212.

Krems, B., C. Charizannis, and K.-D. Entian. 1996. The response regulator-like protein POS9/SKN7 of Saccharomyces cerevisiae is involved in oxidative stress resistance. Curr. Genet. 29: 327-334.

Kyriakis, J.M., P. Baneriee, E. Nikolakaki, T. Dai, E.A. Rubie, M.F. Ahmad, J. Avruch, and J.R. Woodgett. 1994. The stressactivated protein kinase family of c-jun kinases. Nature 369: 156-160.

Lee, J.C., J.T. Laydon, P.C. McDonnell, T.F. Gallagher, S. Kumar, D. Green, D. McNulty, M.J. Blumenthal, J.R. Heys, S.W. Landvatter, J.E. Strickler, M.M. McLaughlin, I.V. Siemens, S.M. Fisher, G.P. Livi, J.R. White, J.L. Adams, and P.R. Young. 1994. A protein kinase involved in the regulation of inflammatory cytokine biosynthesis. Nature 372: 739-746.

Lin, A.A., A. Minden, H. Martinetto, F.-X. Claret, C. LangeCarter, F. Mercurio, G.L. Johnson, and M. Karin. 1995. Iden- 
tification of a dual specificity kinase that activates Jun kinases and p38-Mpk2. Science 268: 966-970.

Lundgren, K., R.M. Walworth, M. Booher, M. Demski, M. Kirschner, and D. Beach. 1991. mik1 and wee1 co-operate in the inhibitory tyrosine phosphorylation of cdc2. Cell 64: 11111122.

Maeda, T., S.M. Wurgler-Murphy, and H. Saito. 1994. A twocomponent system that regulates an osmosensing MAP kinase cascade in yeast. Nature 369: 242-245.

Maeda, T., M. Takekawa, and H. Saito. 1995. Activation of yeast PBS2 MAPKK by MAPKKKs or by binding of an SH3-containing osmosensor. Science 269: 554-558.

Maundrell, K. 1993. Thiamine repressible expression vectors pREP and pRIP for fission yeast. Gene 123: 127-130.

Millar, J.B.A. and P. Russell. 1992. The cdc25 mitotic inducer: an unconventional protein phosphatase. Cell 68: 407-410.

Millar, J.B.A., P. Russell, J.E. Dixon, and K.-L. Guan. 1992. Negative regulation of mitosis by two functionally overlapping PTPases in fission yeast. EMBO T. 11: 4943-4952.

Millar, J.B.A., V. Buck, and M.G. Wilkinson. 1995. Pyp1 and Pyp2 PTPases dephosphorylate an osmosensing MAP kinase controlling cell size at division in fission yeast. Genes \& Dev. 9: 2117-2130.

Minden, A., A. Lin, F.-X. Claret, A. Abo, and M. Karin. 1995. Selective activation of the JNK signalling cascade and c-jun transcritpional activity by the small GTPases Rac and cdc42Hs. Cell 81: 1147-1157.

Molz, L., R. Booher, P. Young, and D. Beach. 1989. cdc2 and the regulation of mitosis: Six interacting mcs genes. Genetics 122: $773-782$

Moreno, S., A. Klar, and P. Nurse. 1991. Molecular genetic analysis of fission yeast Schizosaccharomyces pombe. Meth. Enzymol. 194: 795-823.

Morgan, B.A., N. Bouquin, G.F. Merrill, and L.H. Johnston. 1995. A yeast transcription factor bypassing the requirement for SBF and DSC1/MBF in budding yeast has homology to bacterial signal transduction proteins. EMBO J. 14: 56765689.

Nurse, P. and Y. Bissett. 1981. Gene required in G1 for commitment to cell cycle and in G2 for control of mitosis in fission yeast. Nature 292: $558-560$.

Ota, I.M. and A. Varsharvsky. 1993. A yeast protein similar to bacterial two-component regulators. Science 262: 566-569.

Parkinson, J.S. 1993. Signal transduction systems in bacteria, Cell 73: 857-871.

Pombo, C.M., J.H. Kehrl, I. Sanchez, P. Katz, J. Avruch, I. Zon, J.R. Woodgett, T. Force, and J.R. Kyriakis. 1995. Activation of the SAPK pathway by the human STE20 homolog germinal centre kinase. Nature 377: 750-754.

Posas, F., S.M. Wurgler-Murphy, T. Maeda, E.A. Witten, T.C. Thai, H. Saito. 1996. Yeast HOG1 MAP kinase cascade is regulated by a multi-step phosphorelay mechanism in the SLN1-YPD1-SSK1 "two component" system. Cell 86: 865875.

Prentice, H.L. 1991. High efficiency transformation of Schizosaccharomyces pombe by electroporation. Nucleic Acids Res. 20: 621.

Raingeaud, J., S. Gupta, J.S. Rogers, M. Dickens, J. Han, R.J. Ulevich, and R.J. Davis. 1995. Pro-inflammatory cytokines and environmental stress cause p38 mitogen-activated protein kinase activation by dual phosphorylation on tyrosine and threonine. T. Biol. Chem. 270: 7420-7426.

Raingeaud, J., A.J. Whitmarsh, T. Barrett, B. Dérijard, and R.J. Davis. 1996. MKK3- and MKK6-regulated gene expression is mediated by the $\mathrm{p} 38$ mitogen-activated kinase signal trans- duction pathway. Mol. Cell. Biol. 16: 1247-1255

Rana, A., K. Gallo, P. Godowski, S. Hirai, S. Ohno, L. Zon, J.M. Kyriakis, and J. Avruch. 1996. The mixed lineage kinase SPRK phosphorylates and activates the stress-activated protein kinase activator, SEK-1. I. Biol. Chem. 271: 1902519028.

Rouse, J., P. Cohen, S. Trigon, M. Morange, A. Alonso-Llamazares, D. Zamanillo, T. Hunt, and A. Nebreda. 1994. A novel kinase cascade triggered by stress and heat shock that stimulates MAPKAP kinase- 2 and phosphorylation of the small heat shock proteins. Cell 78: 1027-1037.

Russell, P. and P. Nurse. 1987. Negative regulation of mitosis by wee $1^{+}$, a gene encoding a protein kinase homolog. Cell 49: $559-567$.

Sakata, N., H.R. Patel, N. Terada, A. Aruffo, G.L. Johnson, and E.W. Gelfand. 1995. Selective activation of c-Jun kinase mitogen-activated protein kinase by CD40 on human B cells. J. Biol. Chem. 270: 30823-30828.

Salmeron, A., T.B. Ahmad, G.W. Carlile, D. Pappin, R.P. Narsimhan, and S.C. Ley. 1996. Activation of MEK-1 and SEK-1 by Tpl2 proto-oncogene, a novel MAP kinase kinase kinase. EMBO T. 15: 817-826.

Sambrook, J., E.F. Fritsch, and T. Maniatis. 1989. Molecular cloning: A laboratory manual. Cold Spring Harbor Laboratory Press, Cold Spring Harbor, NY.

Sanchez, I., R.T. Hughes, B.J. Mayer, K. Yee, J.R. Woodgett, J. Avruch, J.M. Kyriakis, and L.I. Zon. 1994. Role of SAPK/ ERK kinase-1 in the stress-activated pathway regulating transcription factor c-jun. Nature 372: 794-798.

Schüller, C., J.L. Brewster, M.R. Alexander, M.C. Gustin, and H. Ruis. 1994. The HOG pathway controls osmotic regulation of transcription via the stress response element (STRE) of the Saccharomyces cerevisiae CTT1 gene. EMBO I. 13: 43824389.

Schuster, S.C., A.A. Noegel, F.O. Oehme, G. Gerisch, and M.I. Simon. 1996. The hybrid kinase DokA is part of the osmotic response system of Dictyostelium. EMBO /. 15: 3880-3889.

Sedgewick, S.G. and B.A. Morgan. 1994. Locating, DNA sequencing, and disrupting yeast genes using tagged Tn1000. Methods Mol. Genet. 3: 131-140.

Shiozaki, K. and P. Russell. 1995. Cell cycle control linked to extracellular environment by MAP kinase pathway in fission yeast. Nature 378: 739-743.

- 1996. Conjugation, meiosis, and the osmotic stress response are regulated by Spc1 kinase through Atf1 transcription factor in fission yeast. Genes \& Dev. 10: 2276-2288.

Sluss, H.K., T. Barrett, B. Dérijard, and R.J. Davis. 1994. Signal transduction by tumor necrosis factor mediated by JNK protein kinases. Mol. Cell. Biol. 14: 5037-5047.

Stock, J.B., A.J. Ninfa, and A.M. Stock. 1989. Protein phosphorylation and regulation of adaptive responses in bacteria. $\mathrm{Mi}$ crobiol. Rev. 53: 450-490.

$\mathrm{Su}$, B., E. Jacinto, M. Hibi, T. Kallunki, M. Karin, and Y. BenNeriah. 1994. JNK is involved in signal integration during costimulation of $\mathrm{T}$ lymphocytes. Cell 77: 727-736.

Takeda, T., T. Toda, K. Kominami, A. Kohnosu, M. Yanagida, and N. Jones. 1995. Schizosaccharomuces pombe atf $1^{+}$encodes a transcription factor required for sexual differentiation and entry into stationary phase. EMBO J. 14: 61936208.

Wang, N., G. Shaulsky, R. Escalente, and W.F. Loomis. 1996. A two-component histidine kinase gene that functions in Dictyostelium development. EMBO J. 15: 3890-3898.

1992. Five novel elements involved in the regulation of mitosis in fission yeast. Mol. Gen. Genet. 232: 440-446. 
Shieh et al.

Wilkinson, M.G., M. Samuels, T. Takeda, T. Toda, M.W. Toone, J.-C. Shieh, J.B.A. Millar, and N.C. Jones. 1996. The Atfl transcription factor is a target for the Styl stress activated MAP kinase pathway in fission yeast. Genes \& Dev. 10: $2289-2301$.

Yamaguchi, K., K. Shirakabe, H. Shibuya, K. Irie, I. Oishi, N. Ueno, T. Taniguchi, E. Nishida, and K. Matsumoto. 1995. Identification of a member of the MAPKKK family as a mediator of TGF- $\beta$ signal transduction. Science 270: 20082011.

Yan, M., T. Dai, J.C. Deak, J.M. Kyriakis, L.I. Zon, J.R. Woodgett, and D.J. Templeton. 1994. Activation of stressactivated protein kinase by MEKK1 phosphorylation of its activator SEK1. Nature 372: 798-800.

Yu, G., R.J. Deschenes, and J.S. Fassler. 1995 . The essential transcription factor, $\mathrm{Mcml}$, is a downstream target of $S \ln 1$, a yeast "two-component" regulator. J. Biol. Chem. 270: 87398743.

Zhang, S., J. Han, M.-A. Sells, J. Chernoff, U.G. Knaus, R.J. Ulevitch, and G.M. Bokoch. 1996. Rho family GTPases regulate p38 mitogen-activated protein kinase through the downstream mediator PAK-1. J. Biol. Chem. 270: 23934-23936. 


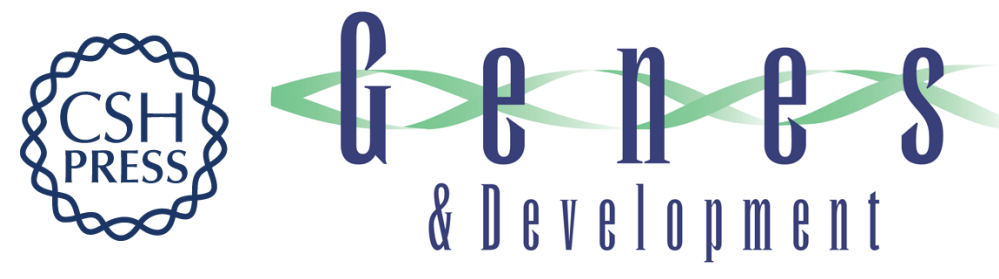

\section{The Mcs4 response regulator coordinately controls the stress-activated Wak1-Wis1-Sty1 MAP kinase pathway and fission yeast cell cycle.}

J C Shieh, M G Wilkinson, V Buck, et al.

Genes Dev. 1997, 11:

Access the most recent version at doi:10.1101/gad.11.8.1008

References This article cites 65 articles, 23 of which can be accessed free at:

http://genesdev.cshlp.org/content/11/8/1008.full.html\#ref-list-1

License

Email Alerting Service

Receive free email alerts when new articles cite this article - sign up in the box at the top right corner of the article or click here.

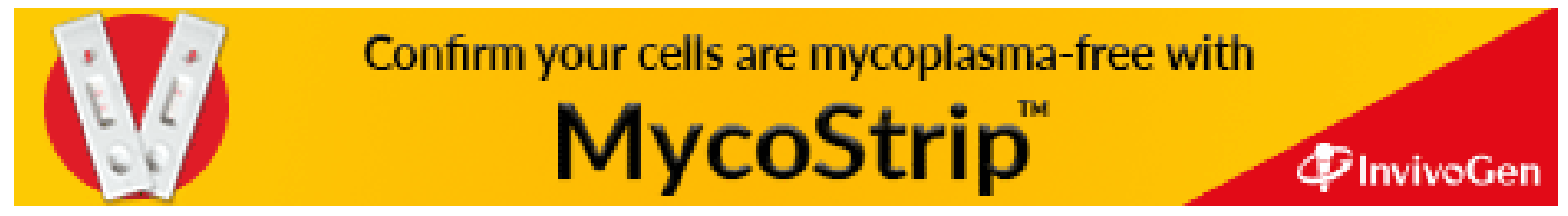

